\title{
In Vivo Measurements With Robust Silicon-Based Multielectrode Arrays With Extreme Shaft Lengths
}

\author{
Gergely Márton, Zoltán Fekete, Richárd Fiáth, Péter Baracskay, István Ulbert, Gábor Juhász, \\ Gábor Battistig, and Anita Pongrácz
}

\begin{abstract}
In this paper, manufacturing and in vivo testing of extreme-long $\mathrm{Si}$-based neural microelectrode arrays are presented. Probes with different shaft lengths $(15-70 \mathrm{~mm})$ are formed by deep reactive ion etching and have been equipped with platinum electrodes of various configurations. In vivo measurements on rats indicate good mechanical stability, robust implantation, and targeting capability. High-quality signals have been recorded from different locations of the cerebrum of the rodents. The accompanied tissue damage is characterized by histology.
\end{abstract}

Index Terms-Neural microelectrode array, deep-brain electrode, silicon-based microelectromechanical system, spike sorting.

\section{INTRODUCTION}

$\mathbf{E}$ LECTRODES, implanted into the central nervous system (CNS) are gaining increasing attention as they are being applied on a widening scale for medical purposes. With deepbrain stimulation, patients with Parkinson's disease or essential tremor can be treated [1], while cortical implants have been employed for control of prosthetic devices [2] and speech restoration [3].

In order to create electronic interfaces with the CNS, siliconbased microstructures are suitable candidates, since they can be provided with widely variable electrode configurations in a precise and reproducible manner, using highly biocompatible materials [4]. These devices allow good quality local field potential, single and multiple unit activity recordings [5], therefore they are frequently applied in experimental neurophysiology as well in vivo, in the CNS of small mammals,

Manuscript received December 12, 2012; revised April 9, 2013; accepted April 24, 2013. The work of A. Pongrácz was supported by the Bolyai János Grant of HAS. The work of I. Ulbert was supported by the French-Hungarian Grant TAMOP-4.2.1.B-11/2/KMR-2011-0002. This work was supported by the Hungarian Science Foundation under Grant OTKA K81354, and by the French-Hungarian Grants ANR-TÉT Neurogen and ANRTÉT Multisca. The associate editor coordinating the review of this paper and approving it for publication was Prof. Aime Lay-Ekuakille.

G. Márton, Z. Fekete, R. Fiáth, I. Ulbert, G. Battistig, and A. Pongrácz are with the Hungarian Academy of Sciences, Budapest 240050, Hungary (e-mail: marton.gergely@ttk.mta.hu; fekete@mfa.kfki.hu; fiath.richard@gmail.com; ulbert@cogpsyphy.hu; battisti@mfa.kfki.hu; pongracz.anita@ttk.mta.hu).

P. Baracsakay is with the Department of Biology, Eötvös Loránd University, Budapest H-1117, Hungary, and also with the Bay Zoltan Nonprofit Ltd. for Applied Research, Budapest H-1116, Hungary (e-mail: baracskayp@gmail.com).

G. Juhász is with the Department of Biology, Eötvös Loránd University, Budapest H-1117, Hungary (e-mail: gjuhasz@dec001.geobio.elte.hu).

Color versions of one or more of the figures in this paper are available online at http://ieeexplore.ieee.org.

Digital Object Identifier 10.1109/JSEN.2013.2260325

e.g. rodents. During experiments performed on mammals with larger brain, such as cats [6] or primates [7], silicon-based microelectrode arrays (MEAs) are typically implanted close to the brain surface, into the cerebral cortex. The application of such probes to access brain regions located more than $1 \mathrm{~cm}$ below the brain surface is highly unusual. For this purpose reinforced silicon-based probes of $1.05 \mathrm{~cm}$ have been presented [8]. In order to interface neural structures located deeper, wire electrodes are more frequently used, as their mechanical robustness is superior to silicon-based devices. However, they lack the benefits of multielectrodes manufactured with microelectromechanical system (MEMS) technology, such as precise, reproducible location of customdesigned electrodes with microscale dimension and good integration capabilities [9].

Polymer-based implantable neural electrode arrays, manufactured with MEMS technology, have also been reported [10], [11]. These flexible devices are able to provide smoother coupling with the neural tissue than silicon. They can adapt to the motions of the brain, thus they cause a less intense immune response and glial scar formation around the probe [12]. However, obtaining precise targeting during penetration into deep-brain regions is difficult or impossible without a more robust support structure [13] or a method that stiffens the implant at least during insertion [14], [15]. Acute experiments are not so sensitive for tissue response like chronic experiments, while easy, precise targeting is an important factor in both cases. These considerations brought the development of silicon-based, deep-brain multielectrode arrays for acute use into our attention.

In this work, we investigated whether the length of functionally appropriate silicon-based MEAs, manufactured using standard MEMS technology can be increased to a much greater scale. Extending shaft thickness and/or width can be a way for providing sufficient mechanical robustness for the implants, but increasing cross-sectional dimensions also increases invasiveness. In order to investigate the functionality of a probe with unusually large dimensions, we have performed in vivo experiments on rat cortex, hippocampus and thalamus. Although the access of these anatomical regions would not require such long shafts, we expect them to be very appropriate targets in order to find out whether these probes cause severe tissue damage, e.g. excessive loss of the nearby neurons. We have performed extracellular recordings in the targeted regions and employed a staining procedure, suitable for indication of damaged cells [16]. 


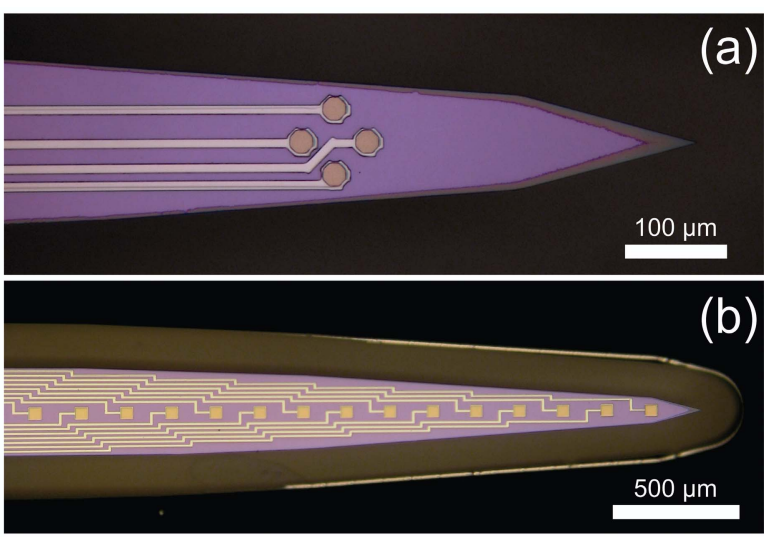

Fig. 1. (a) Tetrode and (b) linear electrode array configurations.

\section{MATERIALS AND Methods}

\section{A. Probe Design}

Studies on the factors affecting mechanical properties of silicon-based neural implants have been published [17], [18]. We intended to manufacture stiff, rather than flexible, singleshaft probes, suitable for the penetration of the meninges (including the dura mater) and precise targeting. Shaft thicknesses were defined by the substrate silicon wafers (200 $\mu \mathrm{m}$ and $380 \mu \mathrm{m}$ ), while their widths and lengths could be freely varied: $206 \mu \mathrm{m}$ and $400 \mu \mathrm{m}$ wide shafts with four different lengths $(15 \mathrm{~mm}, 30 \mathrm{~mm}, 50 \mathrm{~mm}$ and $70 \mathrm{~mm})$ were designed. These parameters have been thoroughly combined. Preliminary study of mechanical characterization of bare silicon probes (without electrodes) of such geometries has been previously presented by our group [19].

The recording electrodes (sites) on the probe tip were arranged as tetrodes (4 electrodes per probe in rhombus vertices) and linear arrays (12 or 16 sites in the midline of the front side of the shaft). Considering the latter, centerto-center distances of the $30 \mu \mathrm{m} \times 30 \mu \mathrm{m}$ and $50 \mu \mathrm{m} \times$ $50 \mu \mathrm{m}$ recording areas were $100 \mu \mathrm{m}$ and $200 \mu \mathrm{m}$, respectively. Tetrodes were optimized for measuring single-unit activities, thus they were more compactly designed: the octagonal sites, $22 \mu \mathrm{m}$ in diagonal, were located $46 \mu \mathrm{m}$ distant from each other. We have formed electrode sites of platinum, which is a commonly used noble metal in this field, because of its biostability [20], [21].

\section{B. Microfabrication and Packaging}

The fabrication technology of the deep brain multielectrodes is based on a single-side, three mask bulk micromachining process sequence that proceeded in three phases. The overall process flow is summarized in Fig 2. $200 \mu \mathrm{m}$ and $400 \mu \mathrm{m}$ thick, double-side polished (100) oriented 4-inch silicon wafers were used for the probe fabrication. The initial phase consisted of thin-film depositions to form the bottom insulating layers, the electrodes and output leads (Fig. 2.A). In the second phase the upper passivation layers were deposited and the contact holes, bonding pads and contour of the probe body were formed by different etching steps (Fig. 2.B). In the last phase deep reactive ion etching (DRIE) was used to define the

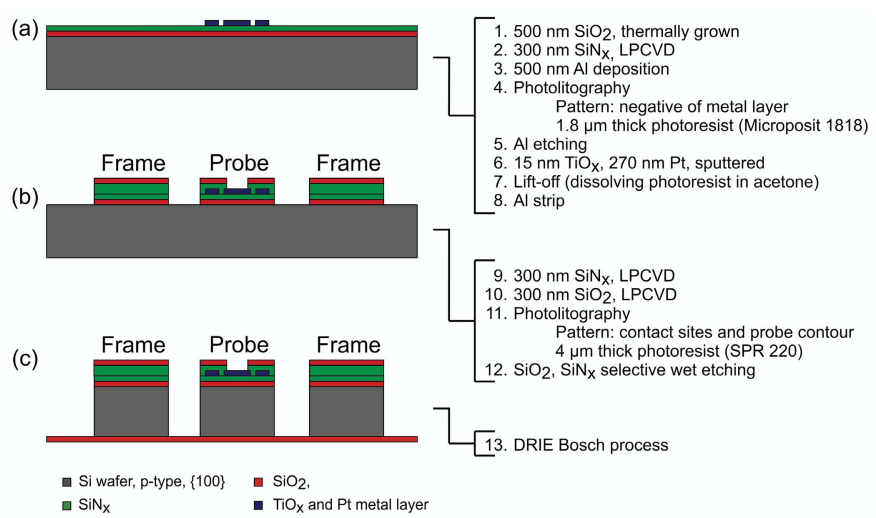

Fig. 2. Technological processes Forming lower insulator and patterned metal layers (a), upper insulator layers, opened at the sites (b), silicon dry etching with Bosch process (c).
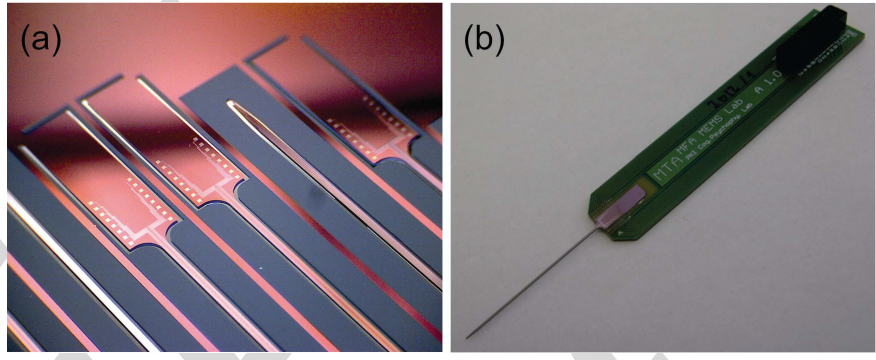

Fig. 3. (a) 16-channel multielectrodes on a micromachined silicon wafer. (b) A packaged silicon-based neural electrode on a PCB with shaft length of $3 \mathrm{~cm}$.

probe shafts and bases (Fig.2.C) followed by the removal of the different masking layers and packaging of the probe.

Contact formation was obtained as follows. In the first step $500 \mathrm{~nm}$ thick $\mathrm{SiO}_{2}$ layer was thermally grown on both sides of the wafer, followed by a deposition of $300 \mathrm{~nm}$ thick low-pressure chemical vacuum deposited (LPCVD) low stress silicon-nitride. The metal layer was then deposited and patterned by lift-off process. The lift-off structure composed of $1.8 \mu \mathrm{m}$ thick photoresist (Microposit 1818) layer over patterned $\mathrm{Al}$ thin film of $500 \mathrm{~nm}$. The metal layer consisted of a $15 \mathrm{~nm}$ thick adhesion layer of $\mathrm{TiO}_{\mathrm{x}}$ and $\mathrm{Pt} . \mathrm{TiO}_{\mathrm{x}}$ was formed by reactive sputtering of $\mathrm{Ti}$ in $\mathrm{O}_{2}\left(\mathrm{Ar} / \mathrm{O}_{2}\right.$ ratio was 80:20) atmosphere. In the same vacuum cycle $270 \mathrm{~nm}$ thick $\mathrm{Pt}$ was sputtered on top of $\mathrm{TiO}_{\mathrm{x}}$. The lift-off was accomplished by dissolving the photoresist pattern in acetone, this process was optimized by using water-cooled substrate holder which diminished the resist distortion during $\mathrm{TiO}_{\mathrm{x}} / \mathrm{Pt}$ sputtering. Subsequently, the removal of Al patterns in four component etching solution and low pressure chemical vapor deposition of $300+300 \mathrm{~nm}$ thick $\mathrm{SiN}_{\mathrm{x}} / \mathrm{SiO}_{2}$ insulating layer stack occurred. Contact holes through the insulating layers were created by selective wet etching processes. By these processing steps, $\mathrm{Pt}$ lines insulated by $\mathrm{SiN}_{\mathrm{x}} / \mathrm{SiO}_{2}$ layers and formation of $\mathrm{Pt}$ contacts have been carried out.

For probe shaping a $500 \mathrm{~nm}$ thick $\mathrm{Al}$ layer was deposited on the front side and patterned by photolithography using $4 \mu \mathrm{m}$ thick SPR220 photoresist. The body of the probe was defined by Al wet etching. SPR220 photoresist was spun also 
TABLE I

The Main Properties of the Meas, Which Have Been Functionally Tested in vivo. Measurements Performed With Probe no. 2 and 6 Are Presented in Details Later. Probe no. 6 and 8 Were Implanted Into the Same Animal, at Different Stereotactic Coordinates

\begin{tabular}{|c|c|c|c|c|c|c|}
\hline Probe no. & $\begin{array}{c}\text { Length } \\
{[\mathrm{mm}]}\end{array}$ & Width $[\mu \mathrm{m}]$ & Thickness $[\mu \mathrm{m}]$ & $\begin{array}{c}\text { Electrode } \\
\text { configuration }\end{array}$ & Tested at & $\begin{array}{c}\text { Implantation target, } \\
\text { in reference to the } \\
\text { bregma }[\mathrm{mm}]\end{array}$ \\
\hline 1 & 1,5 & 206 & 200 & Linear & Lab A & AP: -4.0, ML: 3.0 \\
\hline 2 & 1,5 & 400 & 200 & Linear & Lab A & AP: -4.0, ML: 3.0 \\
\hline 3 & 3 & 400 & 200 & Tetrode & Lab A & AP: -4.0, ML: 3.0 \\
\hline 4 & 3 & 400 & 380 & Tetrode & Lab B & AP: -3.0, ML: 3.2 \\
\hline 5 & 3 & 400 & 200 & Linear & Lab B & AP: -3.0, ML: 3.2 \\
\hline 6 & 3 & 400 & 200 & Tetrode & Lab B & AP: $:-3.0$, ML: 3.0 \\
\hline 7 & 5 & 206 & 380 & Tetrode & Lab B & AP: -3.0, ML: 3.0 \\
\hline 8 & 7 & 400 & 200 & Linear & Lab B & AP: -2.0, ML: 3.5 \\
\hline
\end{tabular}

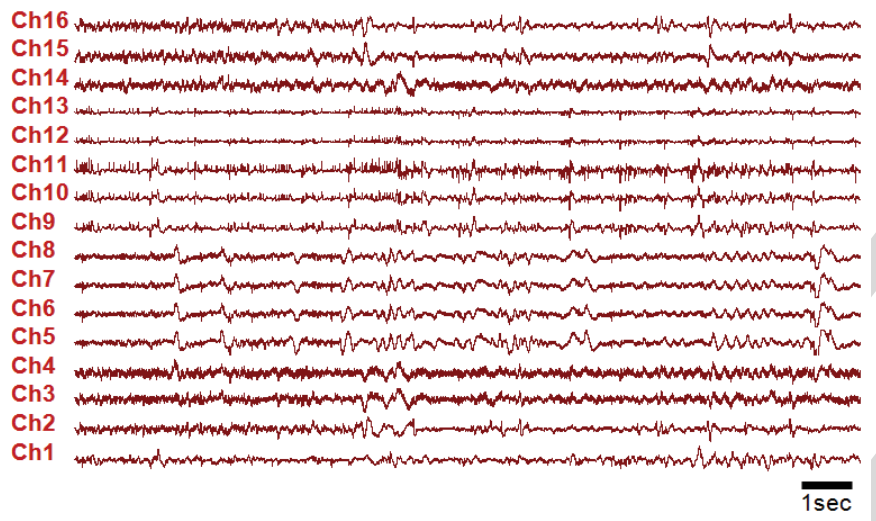

Fig. 4. Representative depth profiles of local field potentials patterns.

on the backside of the wafer used as a stopping layer during the subsequent deep-reactive ion etching of silicon. The 3D micromachining process was performed in an Oxford Plasmalab System 100 chamber using Bosch process. Schematic cross-sectional view of the probe during the fabrication process is shown on Fig. 2.C.

The probes have been flipped out of the wafer and glued onto a printed circuit board (PCB) with a two-component epoxy resin (Araldit AY103/HY956). $50 \mu \mathrm{m}$ thick Al wires have been employed to establish connection between the bonding pads and the PCB leads using a Kulicke-Soffa ultrasonic wire bonder. For the insulation and protection of the $\mathrm{Al}$ wires, the same resin has been used as for the gluing.

\section{Methods of in Vivo Measurements}

Functional tests of eight thus manufactured MEAs have been performed in the cerebrum of anesthetized rats $(n=3+4)$ at two separate laboratories, the Laboratory of Proteomics, Institute of Biology, Eötvös Loránd University (Lab A) and the Comparative Psychophysilogy Laboratory of the Institute of Cognitive Neuroscience and Psychology, RCNS-HAS (Lab B). In both laboratories, animal care and experiments were performed in compliance with order 243/1988 of the Hungarian Government, which is an adaptation of directive

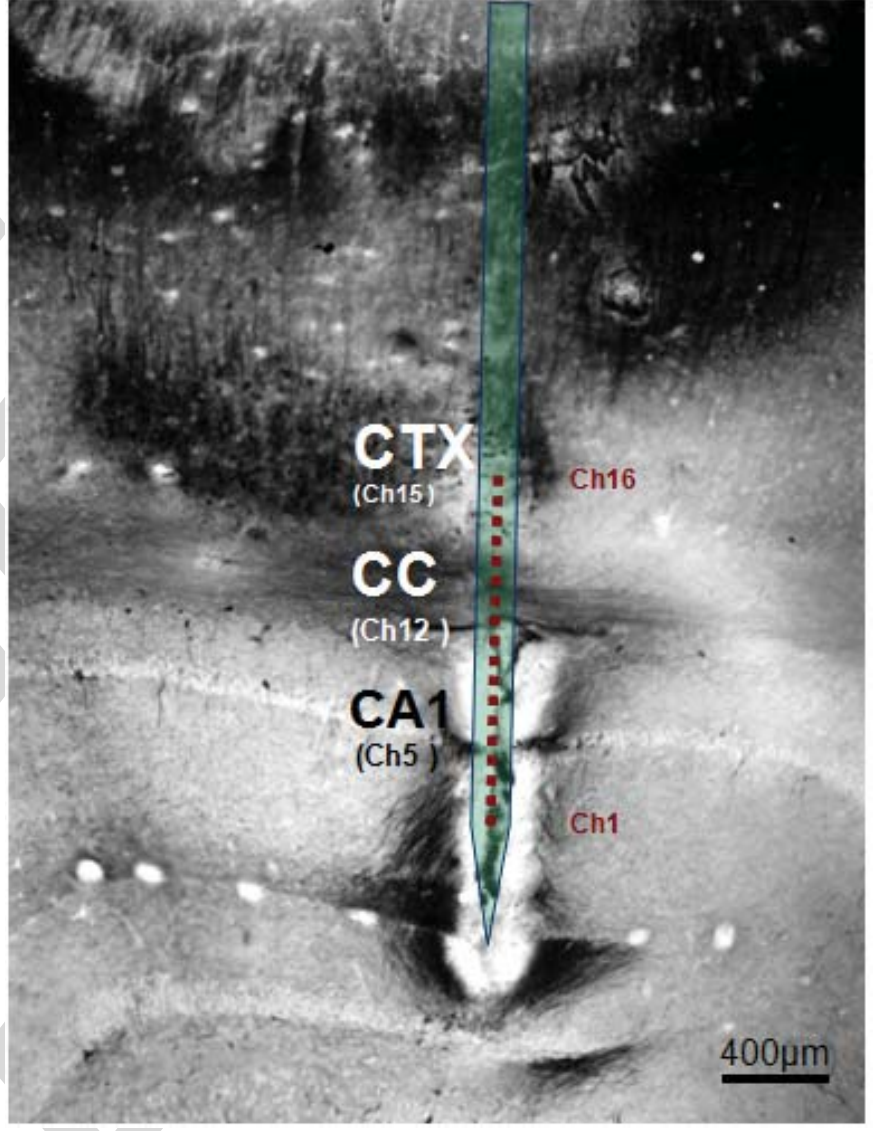

Fig. 5. Histological section showing silicon probe track. The sample has been stained with the Gallyas method.

86/609/EGK of the European Committee Council. Animals have been anesthetized and submitted to stereotactic surgery, targeting cortical, hippocampal and thalamic neural regions. Table 1 summarizes the probes functionally tested in vivo.

At the Laboratory of Proteomics (Lab A), surgical procedures have been carried out as follows. Electrodes were implanted in urethane anesthesia using Kopf stereotactic instrument into the cerebrum of male Sprague-Dawley rats. A midline cut was made in the scalp to expose the skull. 
(a) 2-D Feature Space Plot

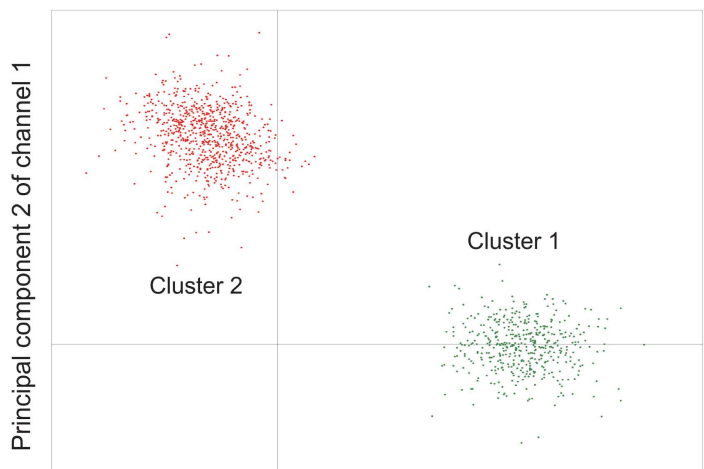

Principal component 1 of channel 1

\section{(c)}

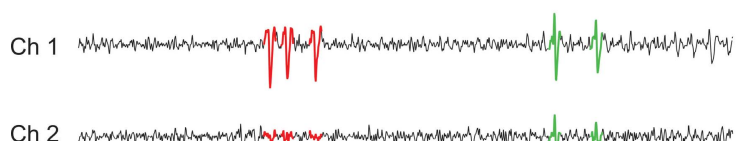

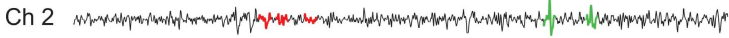

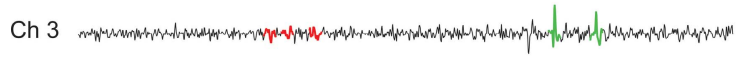

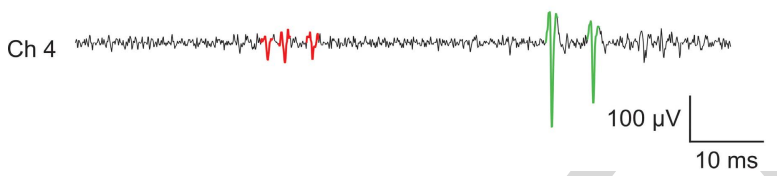

(b)

Average Action

Potential Waveforms
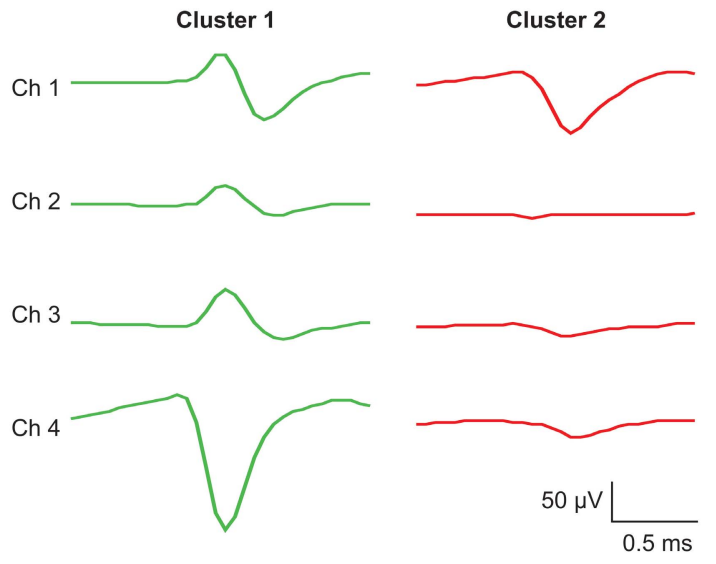

(d)

\section{Autocorrelograms}

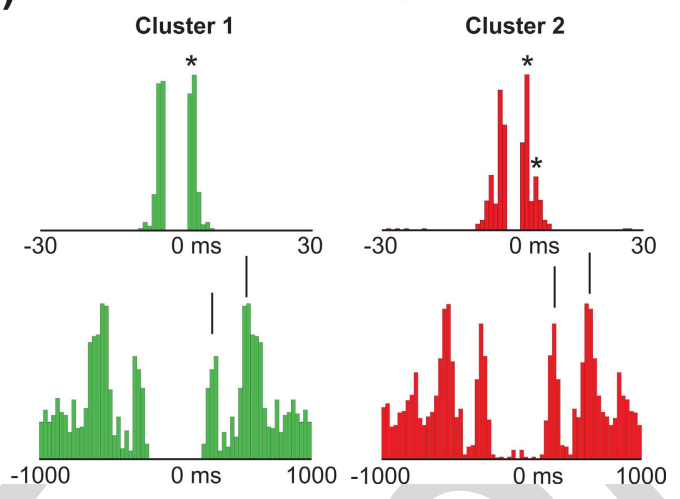

Fig. 6. The result of spike sorting performed on a tetrode recording from the thalamus (a) The 2-D feature space plot with two well separable single unit clusters (red and green cloud of dots). The selected features for spike sorting were the principal components of the spike waveforms. (b) Average action potential waveforms of the two separated unit clusters on different recording channels. Cluster 1 (green unit) has clearly visible action potentials on all four channels with different peak amplitudes. The size of spikes in cluster 2 (red unit) are the biggest on channel 1 and 4 . (c) A 100 ms segment of a bandpass filtered $(500-5000 \mathrm{~Hz})$ unit activity recording with sample spikes of the two isolated clusters. The green unit was a bursting thalamocortical neuron with two action potentials per burst on average, whereas the other thalamic cell (red unit) fired mostly three spikes during one burst. (d) Autocorrelograms of the red and green clusters on two different timescales. The upper pictures show clear refractory periods (no spiking between $0-1$ ms) in case of both of the clusters and several peaks (asterisks) between 2 and $5 \mathrm{~ms}$ that refer to the bursting nature of the thalamocortical neurons during anesthesia. The peaks (arrows) on the bottom autocorrelograms around 250 and $500 \mathrm{~ms}$ implies a strong correlation between the unit activity and the ongoing delta (2-4 $\mathrm{Hz})$ and slow $(0.5-2 \mathrm{~Hz})$ oscillations which are the major brain rhythms in the thalamus during sleep and anesthesia.

A $2.0 \mathrm{~mm}$ diameter hole was drilled in the skull centered $4.0 \mathrm{~mm}$ posterior and $3.0 \mathrm{~mm}$ lateral from the bregma. A $1.2 \mathrm{~mm}$ diameter screw was inserted into the skull above the cerebellum on each side; these served as ground and electrical reference. The dura exposed by the hole was cut and the electrode tip was lowered $2.5-5.5 \mathrm{~mm}$ below the brain surface. Spikes and EEG activity was separately recorded from the same 16 channels ( 32 channel Neuralynx Cheetah data Acquisition system, Neuralynx Inc., Tucson, AZ, USA) with different filter settings. The extracellular action potentials were captured at $30 \mathrm{kHz}$ (amplification 50,000 $\times$, filtering $300 \mathrm{~Hz}-6 \mathrm{kHz}$ ) and the local EEG were recorded continuously at $5 \mathrm{kHz}$ (amplification 10,000×, filtering $1 \mathrm{~Hz}-475 \mathrm{~Hz}$ ). Probes were explanted and rats were sacrificed with a sodium pentobarbital overdose and perfused transcardially with saline followed by $4 \%$ paraformaldehyde (PFA) in phosphate buffer. Brains were removed, stored in 4\% PFA. Using a microtome, $60 \mu \mathrm{m}$ coronal sections were taken. For histological studies, the slices were stained with the Gallyas silver method, a tool for qualitative investigations on the presence of injured neurons [16].

At the Comparative Psychophysilogy Laboratory (Lab B), four Wistar rats were used for the experiments. Initial anesthesia was administered via intraperitoneal injection of a mixture of $37.5 \mathrm{mg} / \mathrm{ml}$ ketamine and $5 \mathrm{mg} / \mathrm{ml}$ xylasine at $0.2 \mathrm{ml} / 100 \mathrm{~g}$ body weight injection volume. The body temperature was maintained at $37{ }^{\circ} \mathrm{C}$ with an electric heating pad. Animals were mounted in a stereotaxic frame (David Kopf) and a $3 \times 3 \mathrm{~mm}$ craniotomy was drilled in the skull above the trunk region of the somatosensory cortex (S1Tr) [22]. The deep anesthesia was maintained with subsequent intramuscularly injected ketamine-xylasine doses $(0.2 \mathrm{ml} / \mathrm{h})$. The probe attached to the micromanipulator was slowly inserted into the cerebrum of the animal without removing the dura mater. Stereotactic coordinates of the targets are presented in table 1 . The brain surface was bathed in 
(a)

Thalamic neuron (VPM)

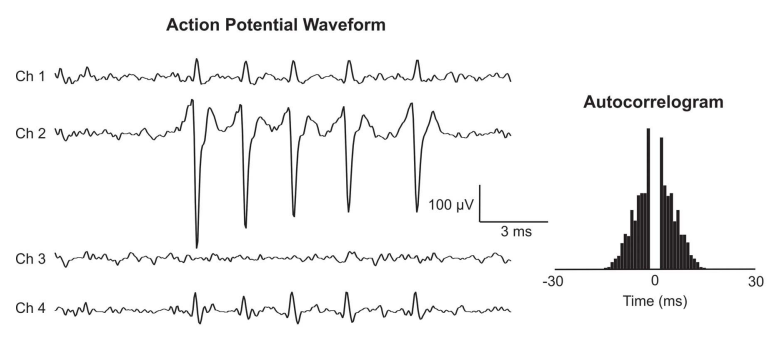

(b)

Thalamic neuron (VPL)
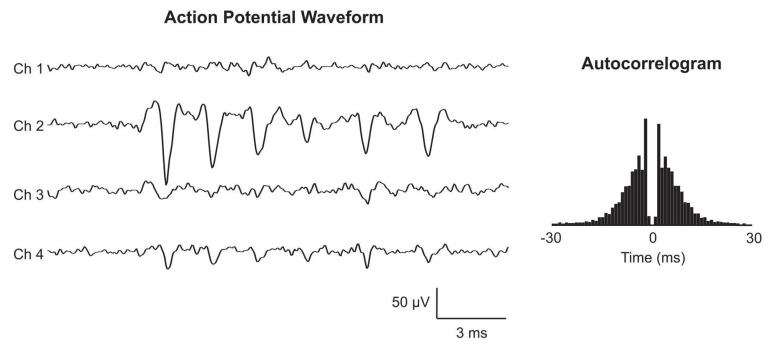

(c)

Thalamic neuron (nRt)

Action Potential Waveform
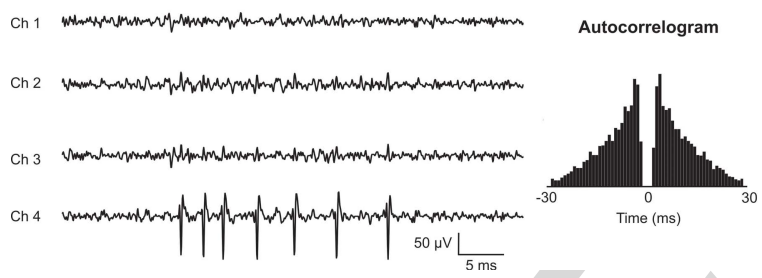

(d)

Cortical neuron (from layer IV)

Action Potential Waveform
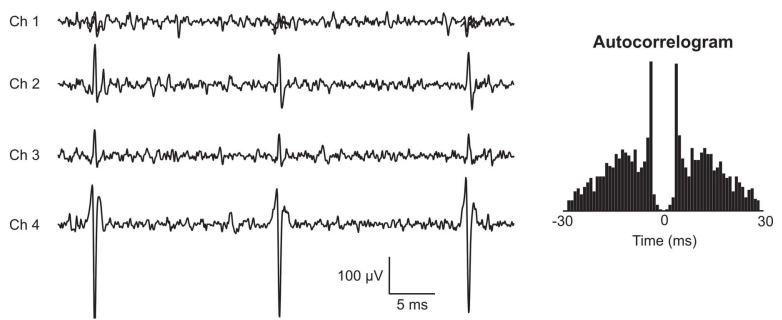

(e)

Cortical neuron (from layer V)
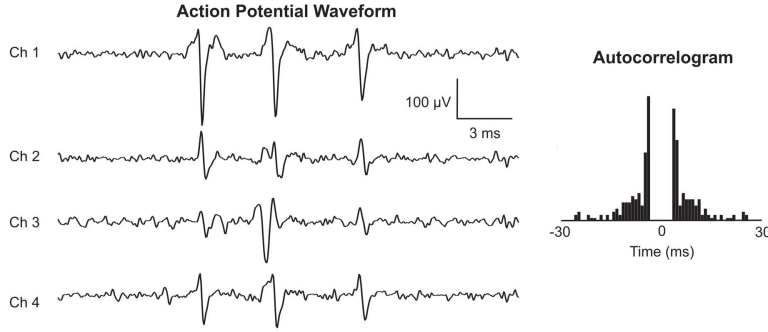

(f)
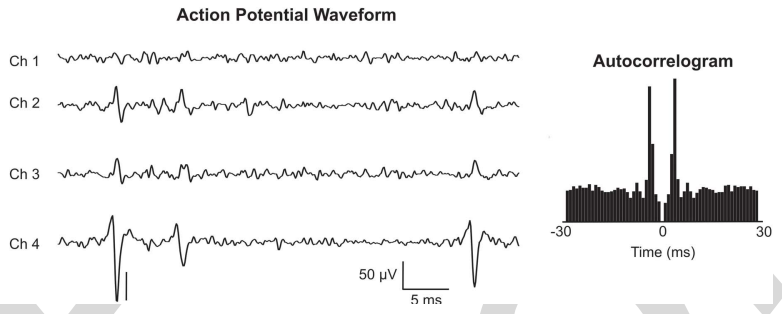

Fig. 7. Representative samples of the spike waveforms (left) and corresponding autocorrelograms (right) recorded with the silicon tetrode from the thalamus and cortex during anesthesia (a)-(f) Peak-to-peak action potential amplitudes ranged from a few dozen microvolts up to 400 microvolts (a) and the spikes of the same unit were in most cases clearly visible on more than one channel. Most of the sorted neurons were bursting cells with $2-6$ spikes per burst.

saline to prevent it from drying. Wide bandwidth electrical activity $(0.1-7000 \mathrm{~Hz})$ with a gain of 1000 was recorded with $20 \mathrm{kHz} /$ channel sampling rate, at 16 bit precision with custom made hardware and software and stored on a hard drive. After the recording sessions the electrodes were withdrawn and the animals were deeply anesthetized. The multiple unit activity (MUA) and single unit activity (SUA) was extracted from the raw wideband signals offline with a band-pass filter (500-5000 Hz, $24 \mathrm{~dB} /$ oct, zeropaseshift) using NeuroScan 4.3 software (Compumedics, El Paso, TX). Spike sorting was used to distinguish single from multiple unit activity. Units were identified and isolated manually with a freely available software (http://www.klusters.sourceforge.net) [23].

\section{RESULTS AND DISCUSSION}

\section{A. In Vivo Measurements - Overview}

During stereotactic surgeries, all of the microelectrodes presented in table 1 have proven to be robust enough for acute use, since neither bending has occurred during implantations, nor any sign of damage could be observed after operations. Various, healthy local field potential (LFP) signals were recorded with these probes. Using tetrodes, single unit activities (spikes) were detected more frequently, as expected, due to the smaller geometric area of their recording sites [24], but spikes have also been recorded with linear probes. In this paper, local field potential recordings and histological studies are presented with a linear MEA (Probe no. 2), unit activity detection and sorting is presented with a tetrode (probe no. 6). The other 6 MEAs have also proven to be functionally appropriate.

\section{B. Local Field Potential Recording and Histology With a Linear Probe}

In this section, measurements with probe no. 3 are presented (its properties are listed in table 1.). Locations of the electrode sites in the brain were first approximated from the recorded waveforms (Fig. 5.). According to our observations, the probe extended into the following anatomical structures.

- Cortex (CTX) - channel 15.

- Corpus callosum (CC) - channel 12.

- The Cornu Ammonis 1 region of the hippocampus (CA1) - channel 5.

Power spectral density calculations on the recorded signals show that the activities were different on all 16 channels. 
These results were in correlation with the histological findings carried out afterwards. With slicing, the tissue including the probe track has been successfully explored. Gallyas staining procedure was employed in order to reveal injured cells around the implantation site (Fig. 6.). The procedure has been only used for visualization, not for quantitative analysis of cell loss.

\section{Spike Detection and Sorting With a Tetrode}

Good quality single and multiple unit activity were recorded from the cortex and thalamus with probe no. 6. A total of 35 cells were recorded from the cortical and thalamic areas (cortex, $\mathrm{n}=13$; thalamus, $\mathrm{n}=22$ ) and two or three clusters could be separated in general from the recorded unit activity at one recording position (Fig. 6.). The mean peak-to-peak amplitude of the averaged action potentials of the cells was $128.9 \pm 54.3 \mu \mathrm{V}$ (range: $43.6-244.5 \mu \mathrm{V}$ ) and the number of spikes in a sorted unit cluster was $1452 \pm 1829$ on average (range: 47-9433). Clusters clearly separated on one plane of the feature space (first three principal components) were selected as putative neurons. Clear refractory periods (1-2 ms) visible on the autocorrelograms of the separated clusters were signs of appropriate spike sorting. In most cases the action potential waveforms of the same unit could be detected on several of the four channels simultaneously (Fig 6.). We also calculated the distribution of the channels where the largest negative peak of the spikes of the recorded neurons was detected, but found no significant differences between the channels (Channel 1: 8 units, $22.9 \%$; Channel 2: 12 units, $34.3 \%$, Channel 3: 5 units, $14.3 \%$; Channel 4: 10 units, $28.5 \%$ ). These results indicate that the spatial position of the tetrode contacts had no effect on the action potential recording capabilities of the probe.

The majority of the neurons were excitatory pyramidal cells $(\mathrm{n}=13)$ and thalamocortical cells $(\mathrm{n}=21)$ with wide spikes (half-amplitude duration: $319 \pm 69.4 \mu \mathrm{s}$, range: $208.5-452 \mu \mathrm{s})$, except for one neuron with narrow action potentials $(164.5 \mu \mathrm{s})$ recorded from the nucleus reticularis thalami (nRt, Fig 7. (c)). The nRt consists of GABAergic inhibitory cells that sends their axon collaterals to several "first order" and "higher order" thalamic nuclei. Representative spike waveforms of neurons recorded from different thalamic nuclei and cortical layers are shown in Fig. 7. Bursting neurons with 2-6 spikes in one burst event are typical to the somatosensory nuclei (VPL, VPM, Po, Fig 7. (a)-(b)) of the thalamus during anesthesia. The nRt neuron fired bursts containing 6-10 action potentials (Fig 7. (c)), while the recorded cortical cells discharged mostly single spikes, spike doublets or triplets (Fig. 7. (d)-(f)). During deep sleep and anesthesia brain rhythms with lower frequencies (slow oscillation, $0.5-2 \mathrm{~Hz}$; delta, 2-4 Hz [25]), can be recorded from the thalamus and cortex and the neuron discharges are time locked to the active phases of these oscillations (Fig. x. (d)).

\section{CONCLUSION}

In vivo electrophysiological measurements on rats with silicon-based neural multielectrode arrays with extreme length, robust mechanical parameters and adequate implantation and targeting capabilities were performed in two separate laboratories. Successful functional tests and histological studies suggest that even though the probes presented here are thicker and wider than commonly used silicon-based devices, they are suitable for obtaining electronic interface with the cerebrum of a small rodent. We suppose that since these probes are of superior length, they are suitable candidates for acute in vivo experiences on animals with larger brain, such as cats or primates, although further tests are necessary to ascertain this assumption.

\section{ACKNOWLEDgement}

We are grateful to Mrs. Károlyné Payer, Mr. András Straszner, Mr. Róbert Hodován and Mr. András Lőrincz for their support in the clean room. We also wish to thank Mr. Attila Nagy and Mr. István Réti for their help in chip packaging. Useful and motivating discussions with Dr. László Grand are greatly acknowledged.

\section{REFERENCES}

[1] J. S. Perlmutter and J. W. Mink, "Deep brain stimulation," Annu. Rev. Neurosci., vol. 29, pp. 229-257, Aug. 2006.

[2] D. M. Taylor, S. I. Tillery, and A. B. Schwartz, "Direct cortical control of 3D neuroprosthetic devices," Science, vol. 296, no. 5574, pp. 1829-1832, Apr. 2002.

[3] F. H. Guenther, J. S. Brumberg, E. J. Wright, A. Nieto-Castanon, J. A. Tourville, M. Panko, R. Law, S. A. Siebert, J. L. Bartels, D. S. Andreasen, P. Ehirim, H. Mao, and P. R. Kennedy, "A wireless brain-machine interface for real-time speech synthesis," PLOS ONE, vol. 4, no. 12, p. e8218, Dec. 2009.

[4] G. Kotzar, M. Freas, P. Abel, A. Fleischman, S. Roy, C. Zorman, J. M. Moran, and J. Melzak, "Evaluation of MEMS materials of construction for implantable medical devices," Biomaterials, vol. 23, no. 13 , pp. 2737-2750, Jul. 2002.

[5] A. Bragin, J. Hetke, C. L. Wilson, D. J. Anderson, J. Engel. Jr., and G. Buzsáki, "Multiple site silicon-based probes for chronic recordings in freely moving rats: Implantation, recording and histological verification," J. Neurosci. Methods, vol. 98, no. 1, pp. 77-82, May 2000.

[6] P. J. Rousche and R. A. Normann, "Chronic recording capability of the Utah Intracortical Electrode Array in cat sensory cortex," J. Neurosci. Methods, vol. 82, no. 1, pp. 1-15, Jul. 1998.

[7] K. Torab, T. S. Davis, D. J. Warren, P. A. House, R. A. Normann, and B. Greger, "Multiple factors may influence the performance of a visual prosthesis based on intracortical microstimulation: Nonhuman primate behavioural experimentation," J. Neural Eng., vol. 8, no. 3, pp. 035001-1-035001-18, Jun. 2011.

[8] M. Hajj-Hassan, V. P. Chodavarapu, and S. Musallam, "Microfabrication of ultra-long reinforced silicon neural electrodes," IET Micro Nano Lett. vol. 4, no. 1, pp. 53-58, Mar. 2009.

[9] D. T. Kewley, M. D. Hills, D. A. Borkholder, I. E. Opris, N. I. Maluf, C. W. Storment, J. M. Bower, and G. T. A. Kovacs, "Plasma-etched neural probes," Sens. Actuators A, Phys., vol. 58, no. 1, pp. 27-35, Jan. 1997.

[10] P. J. Rousche, D. S. Pellinen, D. P. Pivin, Jr., J. C. Williams, R. J. Vetter, and D. R. kirke, "Flexible polyimide-based intracortical electrode arrays with bioactive capability," IEEE Trans. Biomed. Eng., vol. 48, no. 3, pp. 361-371, Mar. 2001.

[11] A. Mercanzini, K. Cheung, D. L. Buhl, M. Boers, A. Maillard, P. Colin, J. C. Bensadoun, A. Bertsch, and P. Renaud, "Demonstration of cortical recording using novel flexible polymer neural probes," Sens. Actuators A, Phys., vol. 143, no. 1, pp. 90-96, 2008.

[12] V. S. Polikov, P. A. Tresco, and W. M. Reichert, "Response of brain tissue to chronically implanted neural electrodes," J. Neurosci. Methods, vol. 148 , no. 1 , pp. 1-18, Oct. 2005.

[13] A. A. Fomani, M. Moradi, S. Assaf, and R. R. Mansour, "3D microprobes for deep brain stimulation and recording," in Proc. Annu. Int. Conf. IEEE Eng. Med. Biol. Soc., Sep. 2010, pp. 1808-1811. 
[14] S. Felix, K. Shah, D. George, V. Tolosa, A. Tooker, H. Sheth, T. Delima, and S. Pannu, "Removable silicon insertion stiffeners for neural probes using polyethylene glycol as a biodissolvable adhesive," in Proc. Annu. Int. Conf. IEEE Eng. Med. Biol. Soc., Aug. 2012, pp. 871-874.

[15] D. Lewitus, K. L. Smith, W. Shain, and J. Kohn, "Ultrafast resorbing polymers for use as carriers for cortical neural probes," Acta Biomater. vol. 7, no. 6, pp. 2483-2491, Jun. 2011.

[16] F. Gallyas, M. Hsu, and G. Buzsaki, "Four modified silver methods for thick sections of formaldehyde-fixed mammalian central nervous tissue: 'Dark' neurons, perikarya of all neurons, microglial cells and capillaries," J. Neurosci. Methods, vol. 50, no. 2, pp. 159-64, Nov. 1993.

[17] M. Welkenhuysen, A. Andrei, L. Ameye, W. Eberle, and B. Nuttin, "Effect of insertion speed on tissue response and insertion mechanics of a chronically implanted silicon-based neural probe," IEEE Trans. Biomed. Eng., vol. 58, no. 11, pp. 3250-3259, Nov. 2011.

[18] K. Najafi and J. F. Hetke, "Strength characterization of silicon microprobes in neurophysiological tissues," IEEE Trans. Biomed. Eng., vol. 37, no. 5, pp. 474-481, May 1990.

[19] Z. Fekete, Z. Hajnal, G. Márton, P. Fürjes, and A. Pongrácz, "Fracture analysis of silicon microprobes designed for deep-brain stimulation," Microelectron. Eng., vol. 103, pp. 160-166, Mar. 2013.

[20] A. M. Dymond, L. E. Kaechele, J. M. Jurist, and P. H. Crandall, "Brain tissue reaction to some chronically implanted metals," J. Neurosurg., vol. 33, no. 5, pp. 574-580, Nov. 1970.

[21] D. R. Merrill, M. Bikson, and J. G. Jefferys, "Electrical stimulation of excitable tissue: Design of efficacious and safe protocols," J. Neurosci. Methods, vol. 141, no. 2, pp. 171-198, Feb. 2005.

[22] G. Paxinos and C. Watson, The Rat Brain in Stereotaxic Coordinates, Compact Sixth Edition. San Diego, CA, USA: Academic, 2009.

[23] L. Hazan, M. Zugaro, and G. Buzsaki, "Klusters, neuroscope, NDmanager: A free software suite for neurophysiological data processing and visualization," J. Neurosci. Methods, vol. 155, no. 2, pp. 207-216, Sep. 2006.

[24] M. A. Moffitt and C. C. McIntyre, "Model-based analysis of cortical recording with silicon microelectrodes," Clinical Neurophysiol., vol. 116 , no. 9, pp. 2240-2250, Sep. 2005

[25] M. Steriade, "The corticothalamic system in sleep," Frontiers Biosci., vol. 8, no. 1, pp. 878-899, 2003.

Gergely Márton received the M.Sc. degree in electrical engineering from the Budapest University of Technology and Economics, Múegyetem rakpart, Hungary, in 2010.

$\mathrm{He}$ is currently pursuing the Ph.D. degree with the János Szentágothai Doctoral School of Neuroscience, Semmelweis University, Budapest, Hungary, and is a Research Assistant with the Institute of Cognitive Neuroscience and Psychology, Research Centre for Natural Sciences, Hungarian Academy of Sciences, Budapest. His current research interests include development of neural interfaces with MEMS technologies.

Zoltán Fekete received the M.Sc. and Ph.D. degrees in electrical engineering from the Budapest University of Technology and Economics, Budapest, Hungary, in 2009 and 2013, respectively.

$\mathrm{He}$ is currently a Research Fellow with the Research Institute of Technical Physics and Material Science, Hungarian Academy of Sciences, Budapest. His current research interests include the development of MEMS devices, silicon and polymer microfluidics, and silicon-based neural microprobes.
Richárd Fiáth received the M.Sc. degree in electrical and computer engineering from the Faculty of Information Technology, Peter Pazmany Catholic University, Budapest, Hungary, in 2009.

$\mathrm{He}$ is currently pursuing the Ph.D. degree with the János Szentágothai Doctoral School of Neuroscience, Semmelweis University, Budapest, and is a Research Assistant with the Institute of Cognitive Neuroscience and Psychology, Research Centre for Natural Sciences, Hungarian Academy of Sciences, Budapest. His current research interests include silicon-based neural interfaces, investigation of thalamocortical interactions, and the physiology of sleep.

Péter Baracskay received the M.S. degree in neurobiology from Eötvös Lóránd University, Budapest, Hungary, in 2007.

He was a Research Assistant with the Department of Medical Chemistry, University of Szeged, Szeged, Hungary, from 2010 to 2011. He is currently with the Bay Zoltan Nonprofit Ltd. for Applied Research, Budapest, and is currently a Graduate Student with the Institute of Biology, Eötvös Lóránd University, Egyetem tér, Hungary.

István Ulbert received the M.Sc. degree in technological physics from the Technical University of Budapest, Budapest, Hungary, in 1988, the M.D degree from the Medical School, Semmelweis University, Budapest, in 1997, and the Ph.D. degree in neurosciences from the Doctoral School, Semmelweis University, in 2002.

He gained scientific experience as a Research Associate with the Albert Einstein College of Medicine, Department of Neuroscience, Bronx, NY, USA, from 1994 to 1996, as a Post-Doctoral Fellow with Stanford University Medical School, Department of Neurosurgery, Stanford, CA, USA, from 1997 to 2000, and as an Instructor of radiology with Harvard University Medical School, Department of Radiology, Massachusetts General Hospital, Boston, MA, USA, from 2000 to 2003 . He is currently a Senior Research Scientist and a Group Leader with the Institute of Cognitive Neuroscience and Psychology, Research Centre for Natural Sciences, Hungarian Academy of Sciences, Budapest, and an Associate Professor with the Faculty of Information Technology, Pázmány Péter Catholic University, Budapest. He has co-authored over 50 articles in peer-reviewed journals and over 250 publications in the forms of conference proceedings, book chapters, posters, and lectures. His current research interests include the development of implantable cortical biosensors for human and animal applications and the investigation of intracortical generators of brain oscillations.

Gábor Juhász, photograph and biography are not available at the time of publication. (4)

Gábor Battistig, photograph and biography are not available at the time of publication.

Anita Pongrácz received the M.Sc. degree in engineering physics from the Technical University of Budapest, Budapest, Hungary, in 2004.

She was a Baseline Process Engineer with the University of California, Berkeley Microfabrication Laboratory, Berkeley, CA, USA, from 2006 to 2007. Her main responsibilities were to design, fabricate, test, and evaluate CMOS test devices. She received the Ph.D. degree in 2010 and is currently a Research Fellow with the Institute of Technical Physics and Material Science, Hungarian Academy of Sciences, Budapest. Her current research interests include microfabrication of neuroMEMS devices. 


\section{AUTHOR QUERIES}

AQ:1 = Images 1, 3, and 4 are not cited in the text. Please indicate where they should be cited. $\mathrm{AQ}: 2$ = Please confirm whether "kirke" is "Kirke" or "Kipke."

$\mathrm{AQ}: 3=$ Please provide biography for the authors "Gábor Juhász and Gábor Battistig" if desired.

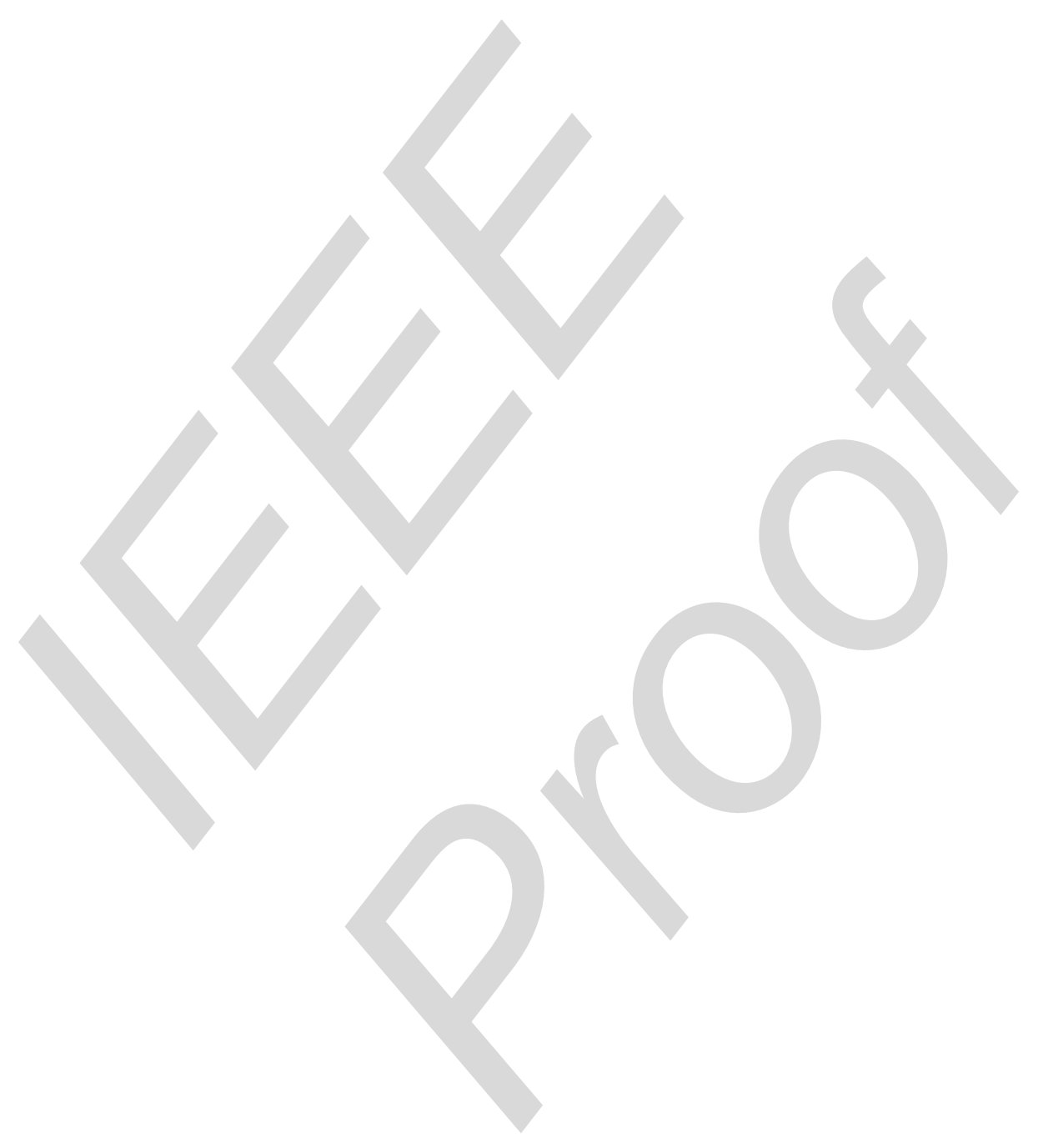




\title{
In Vivo Measurements With Robust Silicon-Based Multielectrode Arrays With Extreme Shaft Lengths
}

\author{
Gergely Márton, Zoltán Fekete, Richárd Fiáth, Péter Baracskay, István Ulbert, Gábor Juhász, \\ Gábor Battistig, and Anita Pongrácz
}

\begin{abstract}
In this paper, manufacturing and in vivo testing of extreme-long $\mathrm{Si}$-based neural microelectrode arrays are presented. Probes with different shaft lengths $(15-70 \mathrm{~mm})$ are formed by deep reactive ion etching and have been equipped with platinum electrodes of various configurations. In vivo measurements on rats indicate good mechanical stability, robust implantation, and targeting capability. High-quality signals have been recorded from different locations of the cerebrum of the rodents. The accompanied tissue damage is characterized by histology.
\end{abstract}

Index Terms-Neural microelectrode array, deep-brain electrode, silicon-based microelectromechanical system, spike sorting.

\section{INTRODUCTION}

$\mathbf{E}$ LECTRODES, implanted into the central nervous system (CNS) are gaining increasing attention as they are being applied on a widening scale for medical purposes. With deepbrain stimulation, patients with Parkinson's disease or essential tremor can be treated [1], while cortical implants have been employed for control of prosthetic devices [2] and speech restoration [3].

In order to create electronic interfaces with the CNS, siliconbased microstructures are suitable candidates, since they can be provided with widely variable electrode configurations in a precise and reproducible manner, using highly biocompatible materials [4]. These devices allow good quality local field potential, single and multiple unit activity recordings [5], therefore they are frequently applied in experimental neurophysiology as well in vivo, in the CNS of small mammals,

Manuscript received December 12, 2012; revised April 9, 2013; accepted April 24, 2013. The work of A. Pongrácz was supported by the Bolyai János Grant of HAS. The work of I. Ulbert was supported by the French-Hungarian Grant TAMOP-4.2.1.B-11/2/KMR-2011-0002. This work was supported by the Hungarian Science Foundation under Grant OTKA K81354, and by the French-Hungarian Grants ANR-TÉT Neurogen and ANRTÉT Multisca. The associate editor coordinating the review of this paper and approving it for publication was Prof. Aime Lay-Ekuakille.

G. Márton, Z. Fekete, R. Fiáth, I. Ulbert, G. Battistig, and A. Pongrácz are with the Hungarian Academy of Sciences, Budapest 240050, Hungary (e-mail: marton.gergely@ttk.mta.hu; fekete@mfa.kfki.hu; fiath.richard@gmail.com; ulbert@cogpsyphy.hu; battisti@mfa.kfki.hu; pongracz.anita@ttk.mta.hu).

P. Baracsakay is with the Department of Biology, Eötvös Loránd University, Budapest H-1117, Hungary, and also with the Bay Zoltan Nonprofit Ltd. for Applied Research, Budapest H-1116, Hungary (e-mail: baracskayp@gmail.com).

G. Juhász is with the Department of Biology, Eötvös Loránd University, Budapest H-1117, Hungary (e-mail: gjuhasz@dec001.geobio.elte.hu).

Color versions of one or more of the figures in this paper are available online at http://ieeexplore.ieee.org.

Digital Object Identifier 10.1109/JSEN.2013.2260325

e.g. rodents. During experiments performed on mammals with larger brain, such as cats [6] or primates [7], silicon-based microelectrode arrays (MEAs) are typically implanted close to the brain surface, into the cerebral cortex. The application of such probes to access brain regions located more than $1 \mathrm{~cm}$ below the brain surface is highly unusual. For this purpose reinforced silicon-based probes of $1.05 \mathrm{~cm}$ have been presented [8]. In order to interface neural structures located deeper, wire electrodes are more frequently used, as their mechanical robustness is superior to silicon-based devices. However, they lack the benefits of multielectrodes manufactured with microelectromechanical system (MEMS) technology, such as precise, reproducible location of customdesigned electrodes with microscale dimension and good integration capabilities [9].

Polymer-based implantable neural electrode arrays, manufactured with MEMS technology, have also been reported [10], [11]. These flexible devices are able to provide smoother coupling with the neural tissue than silicon. They can adapt to the motions of the brain, thus they cause a less intense immune response and glial scar formation around the probe [12]. However, obtaining precise targeting during penetration into deep-brain regions is difficult or impossible without a more robust support structure [13] or a method that stiffens the implant at least during insertion [14], [15]. Acute experiments are not so sensitive for tissue response like chronic experiments, while easy, precise targeting is an important factor in both cases. These considerations brought the development of silicon-based, deep-brain multielectrode arrays for acute use into our attention.

In this work, we investigated whether the length of functionally appropriate silicon-based MEAs, manufactured using standard MEMS technology can be increased to a much greater scale. Extending shaft thickness and/or width can be a way for providing sufficient mechanical robustness for the implants, but increasing cross-sectional dimensions also increases invasiveness. In order to investigate the functionality of a probe with unusually large dimensions, we have performed in vivo experiments on rat cortex, hippocampus and thalamus. Although the access of these anatomical regions would not require such long shafts, we expect them to be very appropriate targets in order to find out whether these probes cause severe tissue damage, e.g. excessive loss of the nearby neurons. We have performed extracellular recordings in the targeted regions and employed a staining procedure, suitable for indication of damaged cells [16]. 


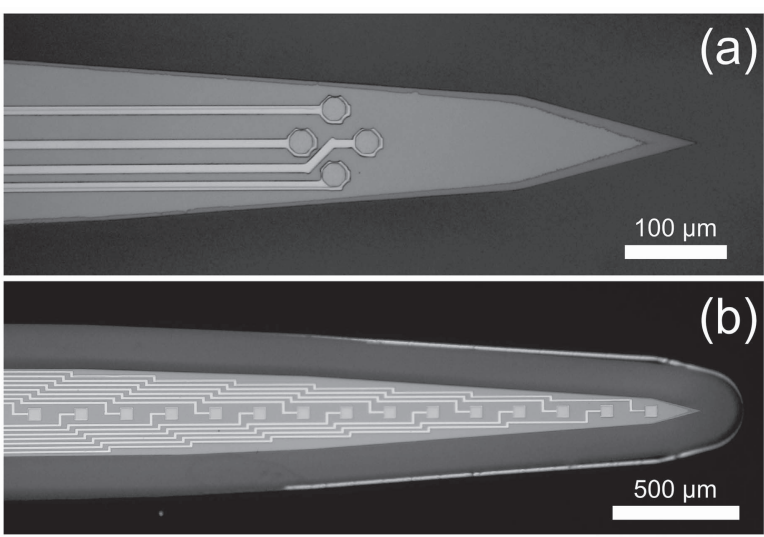

Fig. 1. (a) Tetrode and (b) linear electrode array configurations.

\section{MATERIALS AND Methods}

\section{A. Probe Design}

Studies on the factors affecting mechanical properties of silicon-based neural implants have been published [17], [18]. We intended to manufacture stiff, rather than flexible, singleshaft probes, suitable for the penetration of the meninges (including the dura mater) and precise targeting. Shaft thicknesses were defined by the substrate silicon wafers (200 $\mu \mathrm{m}$ and $380 \mu \mathrm{m}$ ), while their widths and lengths could be freely varied: $206 \mu \mathrm{m}$ and $400 \mu \mathrm{m}$ wide shafts with four different lengths $(15 \mathrm{~mm}, 30 \mathrm{~mm}, 50 \mathrm{~mm}$ and $70 \mathrm{~mm})$ were designed. These parameters have been thoroughly combined. Preliminary study of mechanical characterization of bare silicon probes (without electrodes) of such geometries has been previously presented by our group [19].

The recording electrodes (sites) on the probe tip were arranged as tetrodes (4 electrodes per probe in rhombus vertices) and linear arrays (12 or 16 sites in the midline of the front side of the shaft). Considering the latter, centerto-center distances of the $30 \mu \mathrm{m} \times 30 \mu \mathrm{m}$ and $50 \mu \mathrm{m} \times$ $50 \mu \mathrm{m}$ recording areas were $100 \mu \mathrm{m}$ and $200 \mu \mathrm{m}$, respectively. Tetrodes were optimized for measuring single-unit activities, thus they were more compactly designed: the octagonal sites, $22 \mu \mathrm{m}$ in diagonal, were located $46 \mu \mathrm{m}$ distant from each other. We have formed electrode sites of platinum, which is a commonly used noble metal in this field, because of its biostability [20], [21].

\section{B. Microfabrication and Packaging}

The fabrication technology of the deep brain multielectrodes is based on a single-side, three mask bulk micromachining process sequence that proceeded in three phases. The overall process flow is summarized in Fig 2. $200 \mu \mathrm{m}$ and $400 \mu \mathrm{m}$ thick, double-side polished (100) oriented 4-inch silicon wafers were used for the probe fabrication. The initial phase consisted of thin-film depositions to form the bottom insulating layers, the electrodes and output leads (Fig. 2.A). In the second phase the upper passivation layers were deposited and the contact holes, bonding pads and contour of the probe body were formed by different etching steps (Fig. 2.B). In the last phase deep reactive ion etching (DRIE) was used to define the

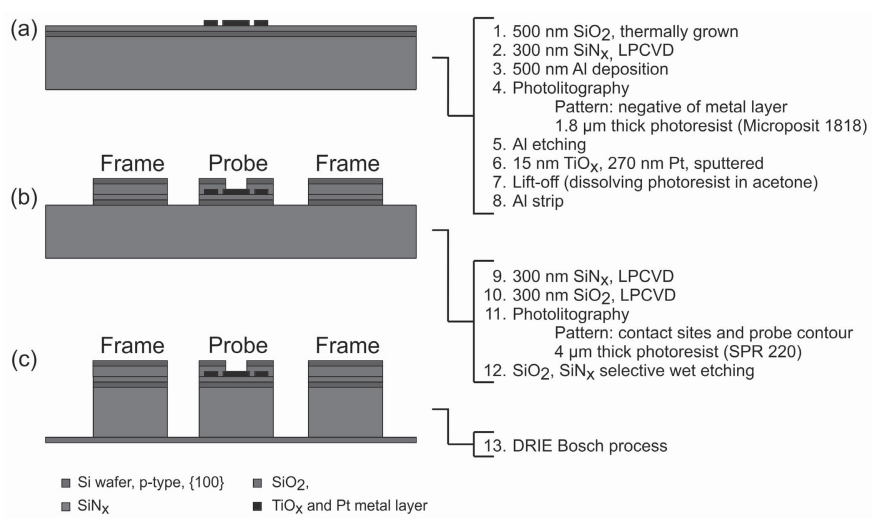

Fig. 2. Technological processes Forming lower insulator and patterned metal layers (a), upper insulator layers, opened at the sites (b), silicon dry etching with Bosch process (c).
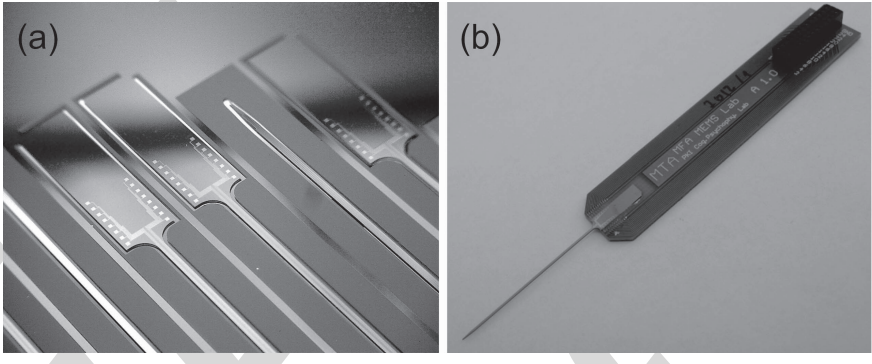

Fig. 3. (a) 16-channel multielectrodes on a micromachined silicon wafer. (b) A packaged silicon-based neural electrode on a PCB with shaft length of $3 \mathrm{~cm}$.

probe shafts and bases (Fig.2.C) followed by the removal of the different masking layers and packaging of the probe.

Contact formation was obtained as follows. In the first step $500 \mathrm{~nm}$ thick $\mathrm{SiO}_{2}$ layer was thermally grown on both sides of the wafer, followed by a deposition of $300 \mathrm{~nm}$ thick low-pressure chemical vacuum deposited (LPCVD) low stress silicon-nitride. The metal layer was then deposited and patterned by lift-off process. The lift-off structure composed of $1.8 \mu \mathrm{m}$ thick photoresist (Microposit 1818) layer over patterned $\mathrm{Al}$ thin film of $500 \mathrm{~nm}$. The metal layer consisted of a $15 \mathrm{~nm}$ thick adhesion layer of $\mathrm{TiO}_{\mathrm{x}}$ and $\mathrm{Pt}$. $\mathrm{TiO}_{\mathrm{x}}$ was formed by reactive sputtering of $\mathrm{Ti}$ in $\mathrm{O}_{2}\left(\mathrm{Ar} / \mathrm{O}_{2}\right.$ ratio was 80:20) atmosphere. In the same vacuum cycle $270 \mathrm{~nm}$ thick $\mathrm{Pt}$ was sputtered on top of $\mathrm{TiO}_{\mathrm{x}}$. The lift-off was accomplished by dissolving the photoresist pattern in acetone, this process was optimized by using water-cooled substrate holder which diminished the resist distortion during $\mathrm{TiO}_{\mathrm{x}} / \mathrm{Pt}$ sputtering. Subsequently, the removal of Al patterns in four component etching solution and low pressure chemical vapor deposition of $300+300 \mathrm{~nm}$ thick $\mathrm{SiN}_{\mathrm{x}} / \mathrm{SiO}_{2}$ insulating layer stack occurred. Contact holes through the insulating layers were created by selective wet etching processes. By these processing steps, $\mathrm{Pt}$ lines insulated by $\mathrm{SiN}_{\mathrm{x}} / \mathrm{SiO}_{2}$ layers and formation of $\mathrm{Pt}$ contacts have been carried out.

For probe shaping a $500 \mathrm{~nm}$ thick $\mathrm{Al}$ layer was deposited on the front side and patterned by photolithography using $4 \mu \mathrm{m}$ thick SPR220 photoresist. The body of the probe was defined by Al wet etching. SPR220 photoresist was spun also 
TABLE I

The Main Properties of the Meas, Which Have Been Functionally Tested in vivo. Measurements Performed With Probe no. 2 and 6 Are Presented in Details Later. Probe no. 6 and 8 Were Implanted Into the Same Animal, at Different Stereotactic Coordinates

\begin{tabular}{|c|c|c|c|c|c|c|}
\hline Probe no. & $\begin{array}{c}\text { Length } \\
{[\mathrm{mm}]}\end{array}$ & Width $[\mu \mathrm{m}]$ & Thickness $[\mu \mathrm{m}]$ & $\begin{array}{c}\text { Electrode } \\
\text { configuration }\end{array}$ & Tested at & $\begin{array}{c}\text { Implantation target, } \\
\text { in reference to the } \\
\text { bregma }[\mathrm{mm}]\end{array}$ \\
\hline 1 & 1,5 & 206 & 200 & Linear & Lab A & AP: -4.0, ML: 3.0 \\
\hline 2 & 1,5 & 400 & 200 & Linear & Lab A & AP: -4.0, ML: 3.0 \\
\hline 3 & 3 & 400 & 200 & Tetrode & Lab A & AP: -4.0, ML: 3.0 \\
\hline 4 & 3 & 400 & 380 & Tetrode & Lab B & AP: -3.0, ML: 3.2 \\
\hline 5 & 3 & 400 & 200 & Linear & Lab B & AP: -3.0, ML: 3.2 \\
\hline 6 & 3 & 400 & 200 & Tetrode & Lab B & AP: -3.0, ML: 3.0 \\
\hline 7 & 5 & 206 & 380 & Tetrode & Lab B & AP: -3.0, ML: 3.0 \\
\hline 8 & 7 & 400 & 200 & Linear & Lab B & AP: -2.0, ML: 3.5 \\
\hline
\end{tabular}

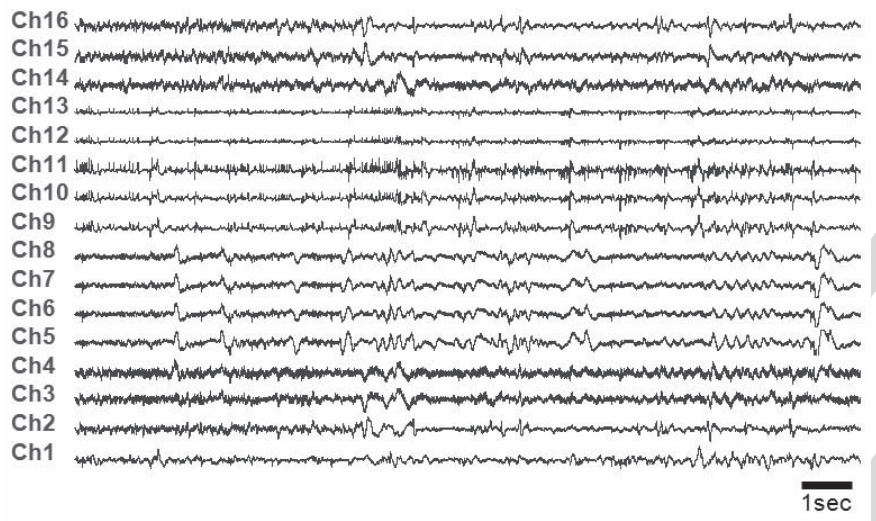

Fig. 4. Representative depth profiles of local field potentials patterns.

on the backside of the wafer used as a stopping layer during the subsequent deep-reactive ion etching of silicon. The 3D micromachining process was performed in an Oxford Plasmalab System 100 chamber using Bosch process. Schematic cross-sectional view of the probe during the fabrication process is shown on Fig. 2.C.

The probes have been flipped out of the wafer and glued onto a printed circuit board (PCB) with a two-component epoxy resin (Araldit AY103/HY956). $50 \mu \mathrm{m}$ thick Al wires have been employed to establish connection between the bonding pads and the PCB leads using a Kulicke-Soffa ultrasonic wire bonder. For the insulation and protection of the $\mathrm{Al}$ wires, the same resin has been used as for the gluing.

\section{Methods of in Vivo Measurements}

Functional tests of eight thus manufactured MEAs have been performed in the cerebrum of anesthetized rats $(n=3+4)$ at two separate laboratories, the Laboratory of Proteomics, Institute of Biology, Eötvös Loránd University (Lab A) and the Comparative Psychophysilogy Laboratory of the Institute of Cognitive Neuroscience and Psychology, RCNS-HAS (Lab B). In both laboratories, animal care and experiments were performed in compliance with order 243/1988 of the Hungarian Government, which is an adaptation of directive

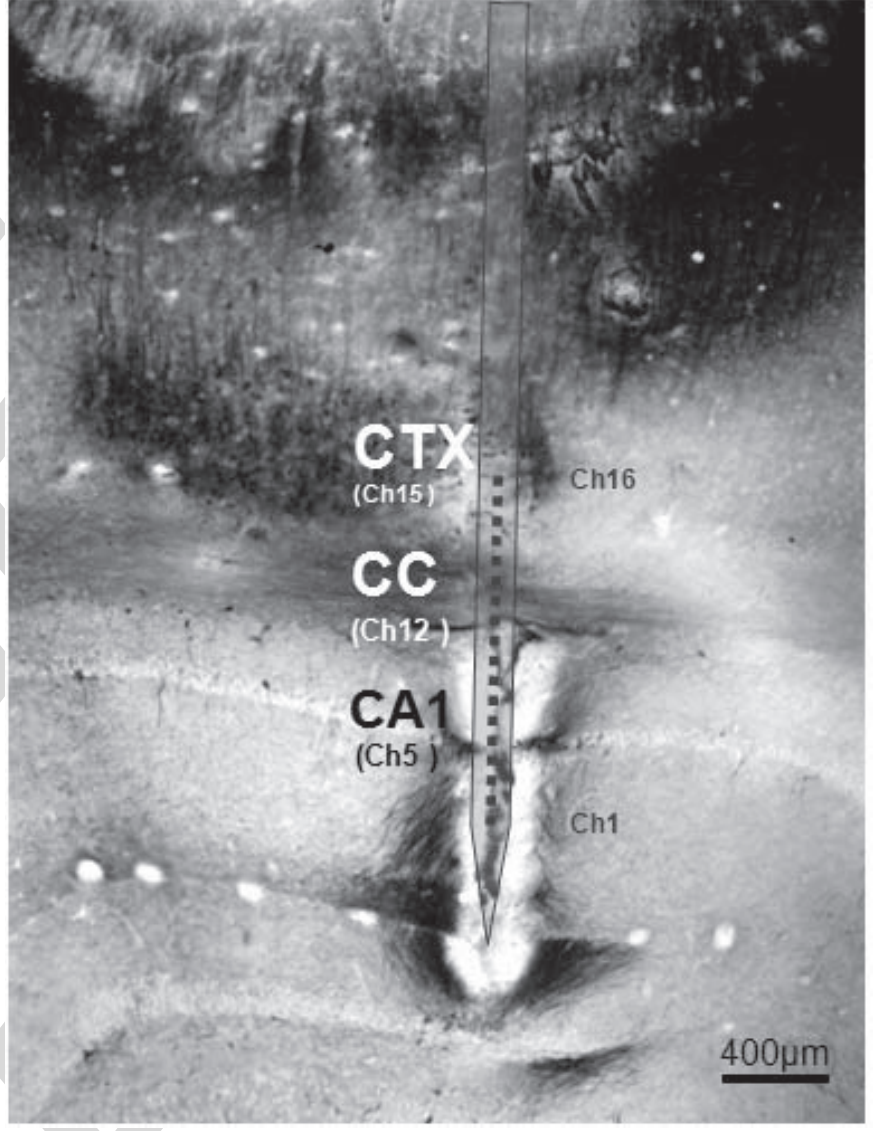

Fig. 5. Histological section showing silicon probe track. The sample has been stained with the Gallyas method.

86/609/EGK of the European Committee Council. Animals have been anesthetized and submitted to stereotactic surgery, targeting cortical, hippocampal and thalamic neural regions. Table 1 summarizes the probes functionally tested in vivo.

At the Laboratory of Proteomics (Lab A), surgical procedures have been carried out as follows. Electrodes were implanted in urethane anesthesia using Kopf stereotactic instrument into the cerebrum of male Sprague-Dawley rats. A midline cut was made in the scalp to expose the skull. 
(a) 2-D Feature Space Plot

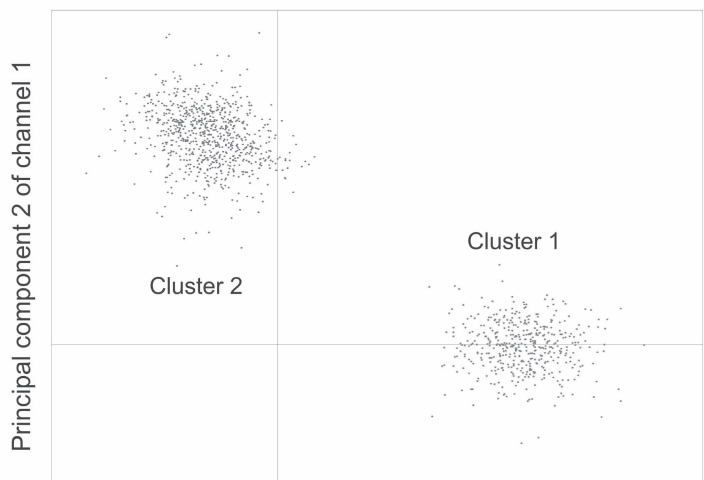

Principal component 1 of channel 1

(c)

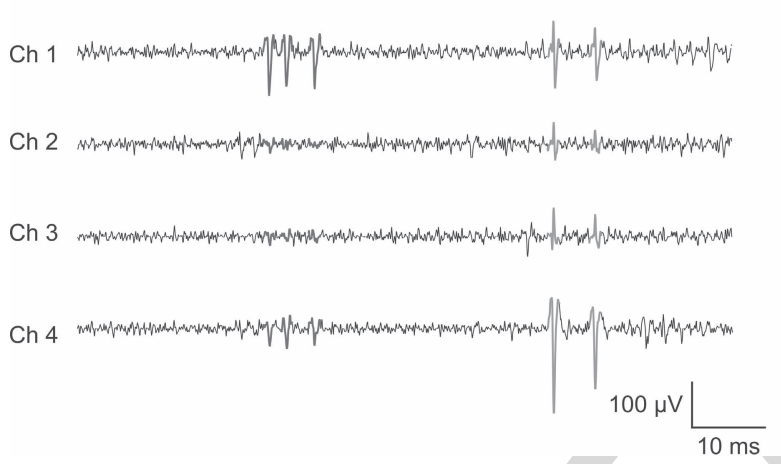

(b)

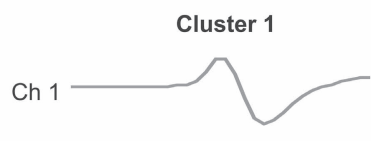

Average Action Potential Waveforms
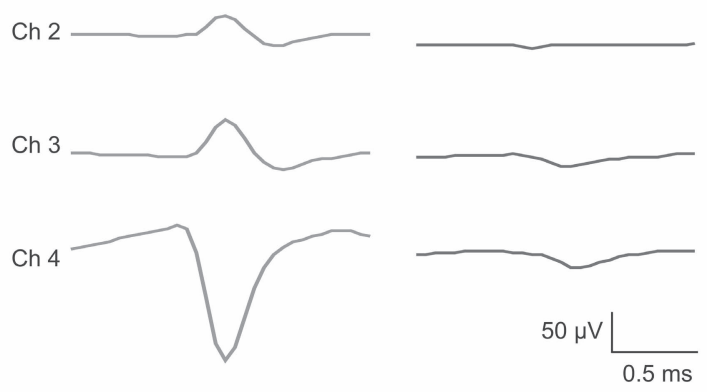

(d)

\section{Autocorrelograms}

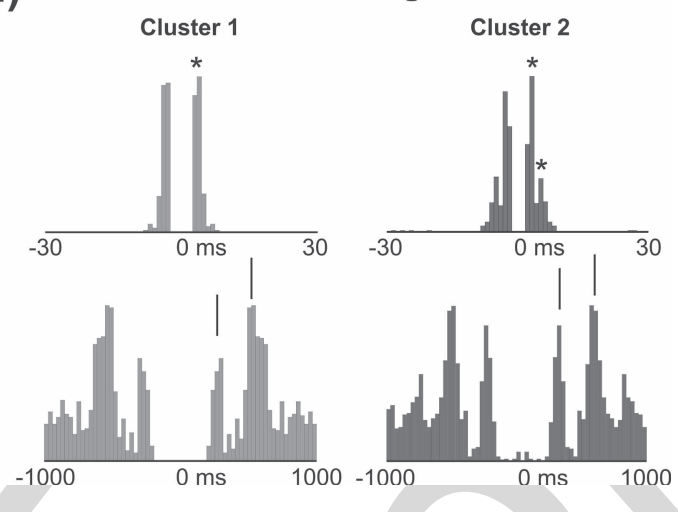

Fig. 6. The result of spike sorting performed on a tetrode recording from the thalamus (a) The 2-D feature space plot with two well separable single unit clusters (red and green cloud of dots). The selected features for spike sorting were the principal components of the spike waveforms. (b) Average action potential waveforms of the two separated unit clusters on different recording channels. Cluster 1 (green unit) has clearly visible action potentials on all four channels with different peak amplitudes. The size of spikes in cluster 2 (red unit) are the biggest on channel 1 and 4 . (c) A 100 ms segment of a bandpass filtered (500-5000 Hz) unit activity recording with sample spikes of the two isolated clusters. The green unit was a bursting thalamocortical neuron with two action potentials per burst on average, whereas the other thalamic cell (red unit) fired mostly three spikes during one burst. (d) Autocorrelograms of the red and green clusters on two different timescales. The upper pictures show clear refractory periods (no spiking between $0-1$ ms) in case of both of the clusters and several peaks (asterisks) between 2 and $5 \mathrm{~ms}$ that refer to the bursting nature of the thalamocortical neurons during anesthesia. The peaks (arrows) on the bottom autocorrelograms around 250 and $500 \mathrm{~ms}$ implies a strong correlation between the unit activity and the ongoing delta (2-4 $\mathrm{Hz})$ and slow $(0.5-2 \mathrm{~Hz})$ oscillations which are the major brain rhythms in the thalamus during sleep and anesthesia.

A $2.0 \mathrm{~mm}$ diameter hole was drilled in the skull centered $4.0 \mathrm{~mm}$ posterior and $3.0 \mathrm{~mm}$ lateral from the bregma. A $1.2 \mathrm{~mm}$ diameter screw was inserted into the skull above the cerebellum on each side; these served as ground and electrical reference. The dura exposed by the hole was cut and the electrode tip was lowered $2.5-5.5 \mathrm{~mm}$ below the brain surface. Spikes and EEG activity was separately recorded from the same 16 channels ( 32 channel Neuralynx Cheetah data Acquisition system, Neuralynx Inc., Tucson, AZ, USA) with different filter settings. The extracellular action potentials were captured at $30 \mathrm{kHz}$ (amplification 50,000×, filtering $300 \mathrm{~Hz}-6 \mathrm{kHz}$ ) and the local EEG were recorded continuously at $5 \mathrm{kHz}$ (amplification 10,000×, filtering $1 \mathrm{~Hz}-475 \mathrm{~Hz}$ ). Probes were explanted and rats were sacrificed with a sodium pentobarbital overdose and perfused transcardially with saline followed by $4 \%$ paraformaldehyde (PFA) in phosphate buffer. Brains were removed, stored in 4\% PFA. Using a microtome, $60 \mu \mathrm{m}$ coronal sections were taken. For histological studies, the slices were stained with the Gallyas silver method, a tool for qualitative investigations on the presence of injured neurons [16].

At the Comparative Psychophysilogy Laboratory (Lab B), four Wistar rats were used for the experiments. Initial anesthesia was administered via intraperitoneal injection of a mixture of $37.5 \mathrm{mg} / \mathrm{ml}$ ketamine and $5 \mathrm{mg} / \mathrm{ml}$ xylasine at $0.2 \mathrm{ml} / 100 \mathrm{~g}$ body weight injection volume. The body temperature was maintained at $37{ }^{\circ} \mathrm{C}$ with an electric heating pad. Animals were mounted in a stereotaxic frame (David Kopf) and a $3 \times 3 \mathrm{~mm}$ craniotomy was drilled in the skull above the trunk region of the somatosensory cortex (S1Tr) [22]. The deep anesthesia was maintained with subsequent intramuscularly injected ketamine-xylasine doses $(0.2 \mathrm{ml} / \mathrm{h})$. The probe attached to the micromanipulator was slowly inserted into the cerebrum of the animal without removing the dura mater. Stereotactic coordinates of the targets are presented in table 1 . The brain surface was bathed in 
(a)

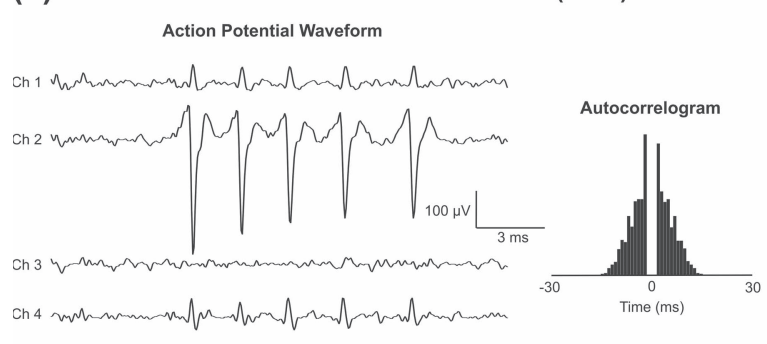

(b)

Thalamic neuron (VPL)
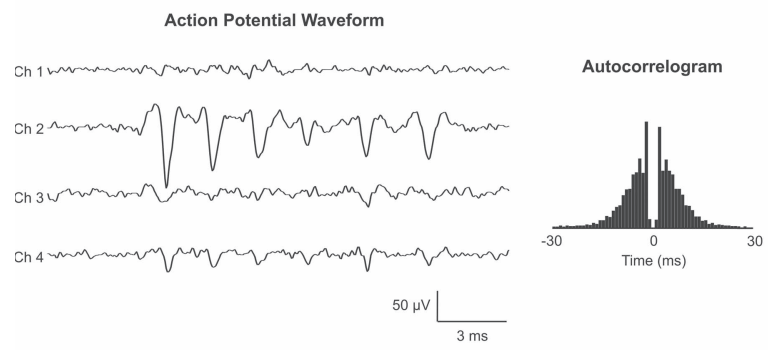

(c)

Thalamic neuron (nRt)

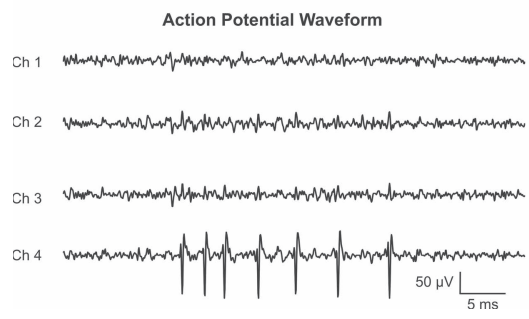

(d) Cortical neuron (from layer IV)
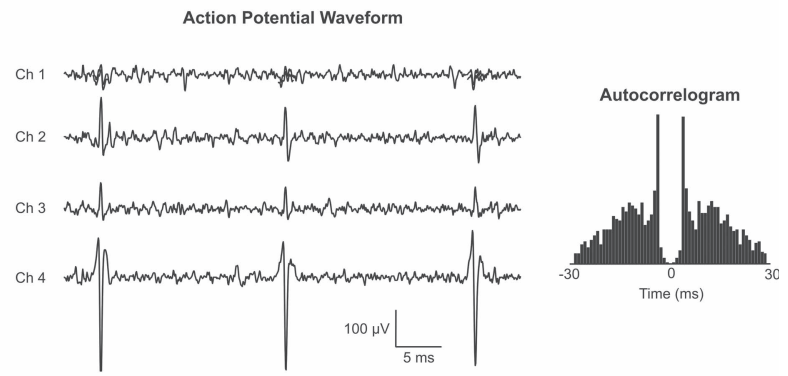

(e)

Cortical neuron (from layer V)
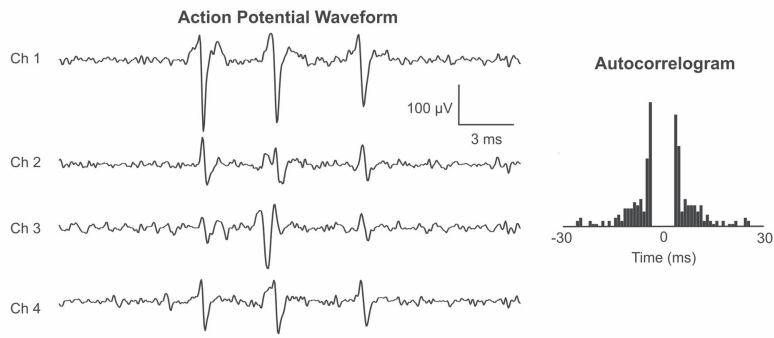

(f)
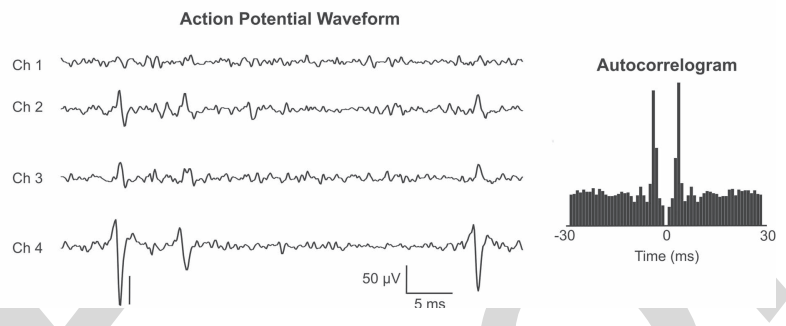

Fig. 7. Representative samples of the spike waveforms (left) and corresponding autocorrelograms (right) recorded with the silicon tetrode from the thalamus and cortex during anesthesia (a)-(f) Peak-to-peak action potential amplitudes ranged from a few dozen microvolts up to 400 microvolts (a) and the spikes of the same unit were in most cases clearly visible on more than one channel. Most of the sorted neurons were bursting cells with $2-6$ spikes per burst.

saline to prevent it from drying. Wide bandwidth electrical activity $(0.1-7000 \mathrm{~Hz})$ with a gain of 1000 was recorded with $20 \mathrm{kHz} /$ channel sampling rate, at 16 bit precision with custom made hardware and software and stored on a hard drive. After the recording sessions the electrodes were withdrawn and the animals were deeply anesthetized. The multiple unit activity (MUA) and single unit activity (SUA) was extracted from the raw wideband signals offline with a band-pass filter (500-5000 Hz, $24 \mathrm{~dB} /$ oct, zeropaseshift) using NeuroScan 4.3 software (Compumedics, El Paso, TX). Spike sorting was used to distinguish single from multiple unit activity. Units were identified and isolated manually with a freely available software (http://www.klusters.sourceforge.net) [23].

\section{RESULTS AND DISCUSSION}

\section{A. In Vivo Measurements - Overview}

During stereotactic surgeries, all of the microelectrodes presented in table 1 have proven to be robust enough for acute use, since neither bending has occurred during implantations, nor any sign of damage could be observed after operations. Various, healthy local field potential (LFP) signals were recorded with these probes. Using tetrodes, single unit activities (spikes) were detected more frequently, as expected, due to the smaller geometric area of their recording sites [24], but spikes have also been recorded with linear probes. In this paper, local field potential recordings and histological studies are presented with a linear MEA (Probe no. 2), unit activity detection and sorting is presented with a tetrode (probe no. 6). The other 6 MEAs have also proven to be functionally appropriate.

\section{B. Local Field Potential Recording and Histology With a Linear Probe}

In this section, measurements with probe no. 3 are presented (its properties are listed in table 1.). Locations of the electrode sites in the brain were first approximated from the recorded waveforms (Fig. 5.). According to our observations, the probe extended into the following anatomical structures.

- Cortex (CTX) - channel 15.

- Corpus callosum (CC) - channel 12.

- The Cornu Ammonis 1 region of the hippocampus (CA1) - channel 5.

Power spectral density calculations on the recorded signals show that the activities were different on all 16 channels. 
These results were in correlation with the histological findings carried out afterwards. With slicing, the tissue including the probe track has been successfully explored. Gallyas staining procedure was employed in order to reveal injured cells around the implantation site (Fig. 6.). The procedure has been only used for visualization, not for quantitative analysis of cell loss.

\section{Spike Detection and Sorting With a Tetrode}

Good quality single and multiple unit activity were recorded from the cortex and thalamus with probe no. 6. A total of 35 cells were recorded from the cortical and thalamic areas (cortex, $\mathrm{n}=13$; thalamus, $\mathrm{n}=22$ ) and two or three clusters could be separated in general from the recorded unit activity at one recording position (Fig. 6.). The mean peak-to-peak amplitude of the averaged action potentials of the cells was $128.9 \pm 54.3 \mu \mathrm{V}$ (range: $43.6-244.5 \mu \mathrm{V}$ ) and the number of spikes in a sorted unit cluster was $1452 \pm 1829$ on average (range: 47-9433). Clusters clearly separated on one plane of the feature space (first three principal components) were selected as putative neurons. Clear refractory periods (1-2 ms) visible on the autocorrelograms of the separated clusters were signs of appropriate spike sorting. In most cases the action potential waveforms of the same unit could be detected on several of the four channels simultaneously (Fig 6.). We also calculated the distribution of the channels where the largest negative peak of the spikes of the recorded neurons was detected, but found no significant differences between the channels (Channel 1: 8 units, $22.9 \%$; Channel 2: 12 units, $34.3 \%$, Channel 3: 5 units, $14.3 \%$; Channel 4: 10 units, $28.5 \%$ ). These results indicate that the spatial position of the tetrode contacts had no effect on the action potential recording capabilities of the probe.

The majority of the neurons were excitatory pyramidal cells $(n=13)$ and thalamocortical cells $(n=21)$ with wide spikes (half-amplitude duration: $319 \pm 69.4 \mu \mathrm{s}$, range: $208.5-452 \mu \mathrm{s})$, except for one neuron with narrow action potentials $(164.5 \mu \mathrm{s})$ recorded from the nucleus reticularis thalami (nRt, Fig 7. (c)). The nRt consists of GABAergic inhibitory cells that sends their axon collaterals to several "first order" and "higher order" thalamic nuclei. Representative spike waveforms of neurons recorded from different thalamic nuclei and cortical layers are shown in Fig. 7. Bursting neurons with 2-6 spikes in one burst event are typical to the somatosensory nuclei (VPL, VPM, Po, Fig 7. (a)-(b)) of the thalamus during anesthesia. The nRt neuron fired bursts containing 6-10 action potentials (Fig 7. (c)), while the recorded cortical cells discharged mostly single spikes, spike doublets or triplets (Fig. 7. (d)-(f)). During deep sleep and anesthesia brain rhythms with lower frequencies (slow oscillation, $0.5-2 \mathrm{~Hz}$; delta, 2-4 Hz [25]), can be recorded from the thalamus and cortex and the neuron discharges are time locked to the active phases of these oscillations (Fig. x. (d)).

\section{CONCLUSION}

In vivo electrophysiological measurements on rats with silicon-based neural multielectrode arrays with extreme length, robust mechanical parameters and adequate implantation and targeting capabilities were performed in two separate laboratories. Successful functional tests and histological studies suggest that even though the probes presented here are thicker and wider than commonly used silicon-based devices, they are suitable for obtaining electronic interface with the cerebrum of a small rodent. We suppose that since these probes are of superior length, they are suitable candidates for acute in vivo experiences on animals with larger brain, such as cats or primates, although further tests are necessary to ascertain this assumption.

\section{ACKNOWLEDgement}

We are grateful to Mrs. Károlyné Payer, Mr. András Straszner, Mr. Róbert Hodován and Mr. András Lőrincz for their support in the clean room. We also wish to thank Mr. Attila Nagy and Mr. István Réti for their help in chip packaging. Useful and motivating discussions with Dr. László Grand are greatly acknowledged.

\section{REFERENCES}

[1] J. S. Perlmutter and J. W. Mink, "Deep brain stimulation," Annu. Rev. Neurosci., vol. 29, pp. 229-257, Aug. 2006.

[2] D. M. Taylor, S. I. Tillery, and A. B. Schwartz, "Direct cortical control of 3D neuroprosthetic devices," Science, vol. 296, no. 5574, pp. 1829-1832, Apr. 2002.

[3] F. H. Guenther, J. S. Brumberg, E. J. Wright, A. Nieto-Castanon, J. A. Tourville, M. Panko, R. Law, S. A. Siebert, J. L. Bartels, D. S. Andreasen, P. Ehirim, H. Mao, and P. R. Kennedy, "A wireless brain-machine interface for real-time speech synthesis," PLOS ONE, vol. 4, no. 12, p. e8218, Dec. 2009.

[4] G. Kotzar, M. Freas, P. Abel, A. Fleischman, S. Roy, C. Zorman J. M. Moran, and J. Melzak, "Evaluation of MEMS materials of construction for implantable medical devices," Biomaterials, vol. 23, no. 13, pp. 2737-2750, Jul. 2002.

[5] A. Bragin, J. Hetke, C. L. Wilson, D. J. Anderson, J. Engel. Jr., and G. Buzsáki, "Multiple site silicon-based probes for chronic recordings in freely moving rats: Implantation, recording and histological verification," J. Neurosci. Methods, vol. 98, no. 1, pp. 77-82, May 2000.

[6] P. J. Rousche and R. A. Normann, "Chronic recording capability of the Utah Intracortical Electrode Array in cat sensory cortex," J. Neurosci. Methods, vol. 82, no. 1, pp. 1-15, Jul. 1998.

[7] K. Torab, T. S. Davis, D. J. Warren, P. A. House, R. A. Normann, and B. Greger, "Multiple factors may influence the performance of a visual prosthesis based on intracortical microstimulation: Nonhuman primate behavioural experimentation," J. Neural Eng., vol. 8, no. 3, pp. 035001-1-035001-18, Jun. 2011.

[8] M. Hajj-Hassan, V. P. Chodavarapu, and S. Musallam, "Microfabrication of ultra-long reinforced silicon neural electrodes," IET Micro Nano Lett., vol. 4, no. 1, pp. 53-58, Mar. 2009.

[9] D. T. Kewley, M. D. Hills, D. A. Borkholder, I. E. Opris, N. I. Maluf, C. W. Storment, J. M. Bower, and G. T. A. Kovacs, "Plasma-etched neural probes," Sens. Actuators A, Phys., vol. 58, no. 1, pp. 27-35, Jan. 1997.

[10] P. J. Rousche, D. S. Pellinen, D. P. Pivin, Jr., J. C. Williams, R. J. Vetter, and D. R. kirke, "Flexible polyimide-based intracortical electrode arrays with bioactive capability," IEEE Trans. Biomed. Eng., vol. 48, no. 3, pp. 361-371, Mar. 2001.

[11] A. Mercanzini, K. Cheung, D. L. Buhl, M. Boers, A. Maillard, P. Colin, J. C. Bensadoun, A. Bertsch, and P. Renaud, "Demonstration of cortical recording using novel flexible polymer neural probes," Sens. Actuators A, Phys., vol. 143, no. 1, pp. 90-96, 2008.

[12] V. S. Polikov, P. A. Tresco, and W. M. Reichert, "Response of brain tissue to chronically implanted neural electrodes," J. Neurosci. Methods, vol. 148, no. 1, pp. 1-18, Oct. 2005.

[13] A. A. Fomani, M. Moradi, S. Assaf, and R. R. Mansour, "3D microprobes for deep brain stimulation and recording," in Proc. Annu. Int. Conf. IEEE Eng. Med. Biol. Soc., Sep. 2010, pp. 1808-1811. 
[14] S. Felix, K. Shah, D. George, V. Tolosa, A. Tooker, H. Sheth, T. Delima, and S. Pannu, "Removable silicon insertion stiffeners for neural probes using polyethylene glycol as a biodissolvable adhesive," in Proc. Annu. Int. Conf. IEEE Eng. Med. Biol. Soc., Aug. 2012, pp. 871-874.

[15] D. Lewitus, K. L. Smith, W. Shain, and J. Kohn, "Ultrafast resorbing polymers for use as carriers for cortical neural probes," Acta Biomater., vol. 7, no. 6, pp. 2483-2491, Jun. 2011.

[16] F. Gallyas, M. Hsu, and G. Buzsaki, "Four modified silver methods for thick sections of formaldehyde-fixed mammalian central nervous tissue: 'Dark' neurons, perikarya of all neurons, microglial cells and capillaries," J. Neurosci. Methods, vol. 50, no. 2, pp. 159-64, Nov. 1993.

[17] M. Welkenhuysen, A. Andrei, L. Ameye, W. Eberle, and B. Nuttin, "Effect of insertion speed on tissue response and insertion mechanics of a chronically implanted silicon-based neural probe," IEEE Trans. Biomed. Eng., vol. 58, no. 11, pp. 3250-3259, Nov. 2011.

[18] K. Najafi and J. F. Hetke, "Strength characterization of silicon microprobes in neurophysiological tissues," IEEE Trans. Biomed. Eng., vol. 37, no. 5, pp. 474-481, May 1990.

[19] Z. Fekete, Z. Hajnal, G. Márton, P. Fürjes, and A. Pongrácz, "Fracture analysis of silicon microprobes designed for deep-brain stimulation," Microelectron. Eng., vol. 103, pp. 160-166, Mar. 2013.

[20] A. M. Dymond, L. E. Kaechele, J. M. Jurist, and P. H. Crandall, "Brain tissue reaction to some chronically implanted metals," J. Neurosurg., vol. 33, no. 5, pp. 574-580, Nov. 1970.

[21] D. R. Merrill, M. Bikson, and J. G. Jefferys, "Electrical stimulation of excitable tissue: Design of efficacious and safe protocols," J. Neurosci. Methods, vol. 141, no. 2, pp. 171-198, Feb. 2005.

[22] G. Paxinos and C. Watson, The Rat Brain in Stereotaxic Coordinates, Compact Sixth Edition. San Diego, CA, USA: Academic, 2009.

[23] L. Hazan, M. Zugaro, and G. Buzsaki, "Klusters, neuroscope, NDmanager: A free software suite for neurophysiological data processing and visualization," J. Neurosci. Methods, vol. 155, no. 2, pp. 207-216, Sep. 2006.

[24] M. A. Moffitt and C. C. McIntyre, "Model-based analysis of cortical recording with silicon microelectrodes," Clinical Neurophysiol., vol. 116, no. 9, pp. 2240-2250, Sep. 2005.

[25] M. Steriade, "The corticothalamic system in sleep," Frontiers Biosci., vol. 8, no. 1, pp. 878-899, 2003.

Gergely Márton received the M.Sc. degree in electrical engineering from the Budapest University of Technology and Economics, Múegyetem rakpart, Hungary, in 2010.

$\mathrm{He}$ is currently pursuing the Ph.D. degree with the János Szentágothai Doctoral School of Neuroscience, Semmelweis University, Budapest, Hungary, and is a Research Assistant with the Institute of Cognitive Neuroscience and Psychology, Research Centre for Natural Sciences, Hungarian Academy of Sciences, Budapest. His current research interests include development of neural interfaces with MEMS technologies.

Richárd Fiáth received the M.Sc. degree in electrical and computer engineering from the Faculty of Information Technology, Peter Pazmany Catholic University, Budapest, Hungary, in 2009.

$\mathrm{He}$ is currently pursuing the Ph.D. degree with the Janos Szentágothai Doctoral School of Neuroscience, Semmelweis University, Budapest, and is a Research Assistant with the Institute of Cognitive Neuroscience and Psychology, Research Centre for Natural Sciences, Hungarian Academy of Sciences, Budapest. His current research interests include silicon-based neural interfaces, investigation of thalamocortical interactions, and the physiology of sleep.

Péter Baracskay received the M.S. degree in neurobiology from Eötvös Lóránd University, Budapest, Hungary, in 2007.

He was a Research Assistant with the Department of Medical Chemistry, University of Szeged, Szeged, Hungary, from 2010 to 2011. He is currently with the Bay Zoltan Nonprofit Ltd. for Applied Research, Budapest, and is currently a Graduate Student with the Institute of Biology, Eötvös Lóránd University, Egyetem tér, Hungary.

István Ulbert received the M.Sc. degree in technological physics from the Technical University of Budapest, Budapest, Hungary, in 1988, the M.D. degree from the Medical School, Semmelweis University, Budapest, in 1997, and the Ph.D. degree in neurosciences from the Doctoral School, Semmelweis University, in 2002 .

He gained scientific experience as a Research Associate with the Albert Einstein College of Medicine, Department of Neuroscience, Bronx, NY, USA from 1994 to 1996, as a Post-Doctoral Fellow with Stanford University Medical School, Department of Neurosurgery, Stanford, CA, USA, from 1997 to 2000, and as an Instructor of radiology with Harvard University Medical School, Department of Radiology, Massachusetts General Hospital, Boston, MA, USA, from 2000 to 2003. He is currently a Senior Research Scientist and a Group Leader with the Institute of Cognitive Neuroscience and Psychology, Research Centre for Natural Sciences, Hungarian Academy of Sciences, Budapest, and an Associate Professor with the Faculty of Information Technology, Pázmány Péter Catholic University, Budapest. He has co-authored over 50 articles in peer-reviewed journals and over 250 publications in the forms of conference proceedings, book chapters, posters, and lectures. His current research interests include the development of implantable cortical biosensors for human and animal applications and the investigation of intracortical generators of brain oscillations.

Gábor Juhász, photograph and biography are not available at the time of publication.

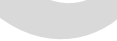

Gábor Battistig, photograph and biography are not available at the time of publication.

Anita Pongrácz received the M.Sc. degree in engineering physics from the Technical University of Budapest, Budapest, Hungary, in 2004.

She was a Baseline Process Engineer with the University of California, Berkeley Microfabrication Laboratory, Berkeley, CA, USA, from 2006 to 2007. Her main responsibilities were to design, fabricate, test, and evaluate CMOS test devices. She received the Ph.D. degree in 2010 and is currently a Research Fellow with the Institute of Technical Physics and Material Science, Hungarian Academy of Sciences, Budapest. Her current research interests include microfabrication of neuroMEMS devices. 


\section{AUTHOR QUERIES}

AQ:1 = Images 1, 3, and 4 are not cited in the text. Please indicate where they should be cited.

$\mathrm{AQ}: 2$ = Please confirm whether "kirke" is "Kirke" or "Kipke."

$\mathrm{AQ}: 3=$ Please provide biography for the authors "Gábor Juhász and Gábor Battistig" if desired.

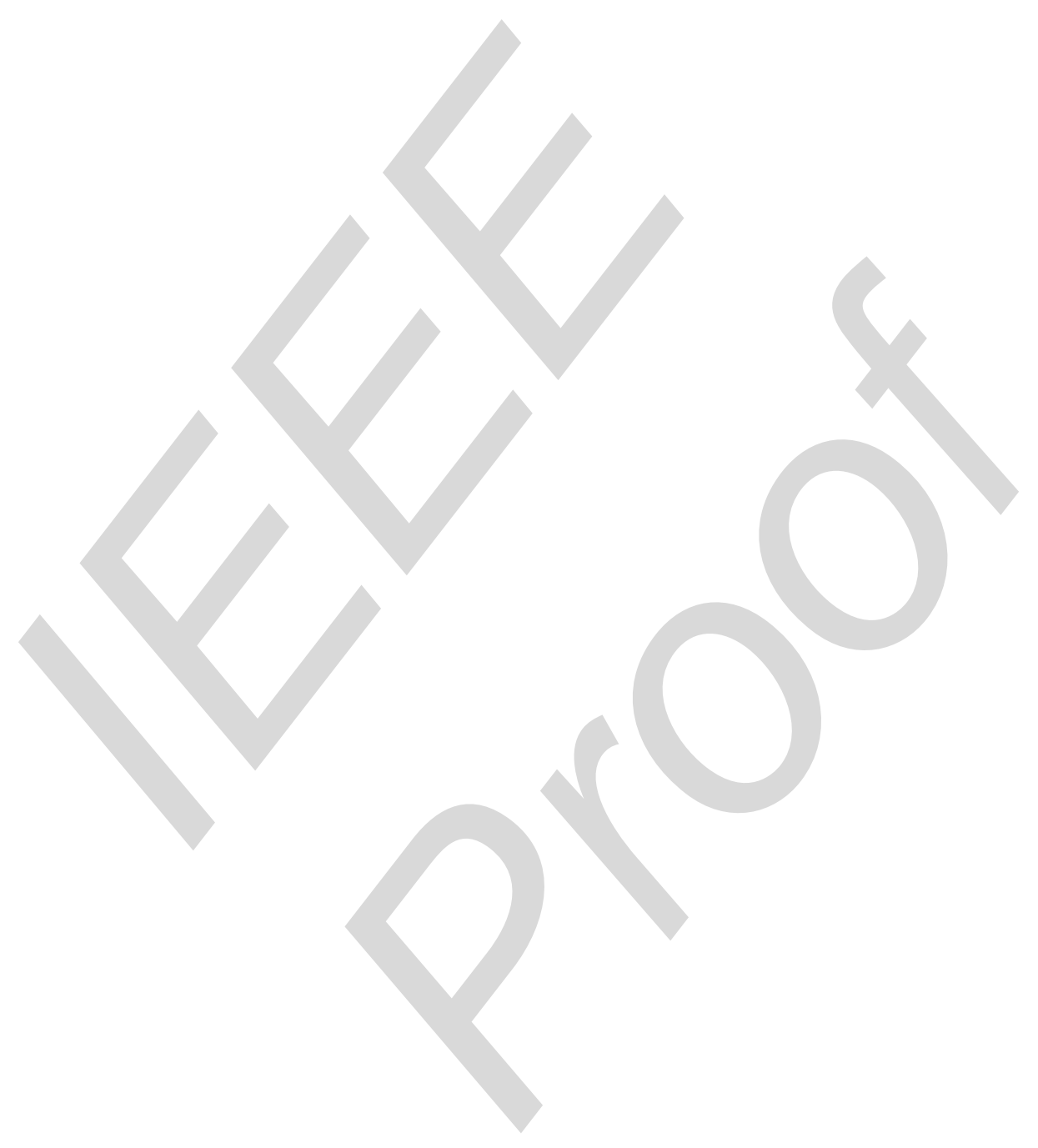

